\title{
LA PROBLEMÁTICA CHANKA: ANÁLISIS SOCIOPOLÍTICO DE LAS SOCIEDADES TARDÍAS DE LA SIERRA CENTRO SUR ANDINA
}

\author{
Pieter D. VAN Dalen LUNA ${ }^{1}$ \\ Universidad NaCIONAL MAYOR DE SAN MARCOS \\ PVANDALEN2@HOTMAIL.COM
}

\section{RESUMEN}

Se presenta un panorama sobre la arqueología prehispánica tardía de la sierra centro sur peruana, territorio comúnmente denominado como "Chanka", en el cual se desarrollaron numerosas entidades sociopolíticas; algunas enfrentadas entre sí, mientras que otras interactuaban social y culturalmente. El Tawantinsuyu conquistó estos territorios tras la derrota de los Chankas en el Cusco, para lo cual algunos de los vecinos de los Chankas (como los quichuas), se aliaron al expansivo estado cusqueño. En base a la revisión de los datos, el territorio de desarrollo de los Chankas fue la actual provincia de Andahuaylas y no la actual región de Ayacucho.

Palabras claves: arqueología, Intermedio tardío, sierra central, Tawantinsuyu, Chanka.

\section{Abstract}

It presents a view on the prehispanic archeology of the Peruvian southeastern center, commonly called "Chanka", in which numerous socio-political entities were developed; Some facing each other, while others interacted socially and culturally. The Tawantinsuyu conquered these territories after the defeat of the Chankas in Cusco, for which some of the neighbors of the Chankas (like the Quichuas), allied themselves with the expansive state cusqueño. Based on the review of the data, the development territory of the Chankas was the present province of Andahuaylas and not the current region of Ayacucho.

KeYwords: archeology, Late Intermediate, central highlands, Tawantinsuyu, Chanka.

1. Licenciado en Arqueología por la Universidad Nacional Mayor de San Marcos. Bachiller en Educación (Historia), Universidad Nacional de Educación (La Cantuta). Maestrías en: Arqueología Andina, Estudios Amazónicos y Gestión del Patrimonio Cultural (UNMSM), Doctorado en Ciencias Sociales (UNMSM). Docente permanente del departamento Académico de Arqueología, Facultad de Ciencias Sociales, Universidad Nacional Mayor de San Marcos. Director del Museo de Arqueología y Antropología de San Marcos. 


\section{INTRODUCCIÓN}

El periodo Intermedio Tardío, definido por Rowe (1960), caracterizado por el desarrollo de numerosas entidades sociopolíticas en todos los Andes, de grandes extensiones en la Costa (centro y norte) y pequeñas en las zonas altoandinas. Entre las más representativas figuran: Chimú, Tallán, Lambayeque, Chancay, Cajamarca, Chachapoyas, Luya Chillao, Wamalíes, Guánuco, Chupachus, Atavillos, Canta, Ichma, Huarochirí, Yauyos, Asto, Guarco, Runaguanac, Wankas, Chinchaycocha, Tarama, Laraos, Chankas, Aymaraes, Quichuas, Soras, Rucanas, Collas, Lupaqas, Puquinas, Churajón, Collaguas, Chiribaya y los propios Incas en su fase pre-imperial. Consideramos a la sierra centro sur andina como aquella extensión territorial conformada por los actuales departamentos de Ayacucho, Apurímac y Huancavelica, aunque para el presente trabajo nos centraremos en los dos primeros a fin de caracterizar o lograr una aproximación para el entendimiento de las sociedades que se desarrollaron en periodos tardíos en este territorio, los cuales son conocidos como Chankas.

Hablar de los Chankas² es referirse a una de las sociedades andinas prehispánicas tardías más importantes, aquella sociedad que estuvo a punto de cambiar la historia andina, con su famosa guerra contra el Cusco incásico pre expansivo. Casi el 90\% de cronistas que se refieren al Tawantinsuyu hablan de esta famosa guerra en la cual los Chankas al mando de Uscovilca y Ancovilca (aunque algunos cronistas hablan también de Tomayguaraca y Astoguaraca, así como de sus capitanes: Malma, Rapa, Yanavilca, Teclovilca y Guamanguaraca (Betanzos; 1551: capítulo VI), llegaron al Cusco para atacar al naciente estado Tawantinsuyano. Luego de algunas batallas, los Incas, al mando de Tito Cusi Yupanqui (más tarde Pachacuteq) recibieron el apoyo de numerosos pueblos vecinos (entre ellos de los Quechuas que eran enemigos de los Chankas), con lo cual derrotaron a los Chancas y capturaron a sus jefes y curacas principales. Luego de esto, Pachacuteq persigue a los Chankas hasta Andahuaylas donde los derrota finalmente y los somete, para luego ocupar territorios de otros grupos como los Vilcas, Soras, Rucanas, Antamarkas, etc. Esta historia es muy conocida entre los investigadores, como lo es también a partir de las crónicas sobre la huida de un grupo de Chankas dirigidos por Anco Ayllo hacia la Amazonía para luego instalarse en Lamas (San Martín). Los detalles de estas historias no las vamos a tocar por no corresponder al objetivo del presente artículo. Sin embargo, es poco lo que se conoce sobre los Chankas, su sistema de organización sociopolítica, distribución espacial, sus manifestaciones culturales y las relaciones que mantuvo con otros grupos de los departamentos de Ayacucho, Apurímac y Huancavelica. A partir de las fuentes etnohistóricas, los arqueólogos han venido definiendo que existieron en estos tres departamentos varios grupos sociopolíticos, etnias o naciones, entre estos: Astos, Ankaras o Angaraes, Wankas, y Chocorbos (Huancavelica); Rukanas Antamarkas, Rukanas Laramates, Soras, Pocras, Vilcas, Chankas (Ayacucho); Chankas, Aymaraes, Quechuas (Apurímac). Sin embargo, los investigadores plantean que estos grupos formaron una confederación conocida como "Confederación Chanka", la cual fue la que hizo la guerra contra el Cusco.

En la actualidad, por lo general, se toma el nombre Chanka para denominar a todas las ocupaciones del Intermedio Tardío en los tres departamentos, sin mencionar a los otros grupos y cuando se les menciona se les toma como integrados a los Chankas. En este sentido las problemáticas de investigación que tenemos es la de identificar las características socioculturales del Intermedio Tardío en los departamentos de Ayacucho, Huancavelica y Apurímac; así como definir si este territorio fue ocupado por los Chankas o existieron otros grupos; definir de haber existido la confederación Chanka, como se organizaba esta y cuáles eran las relaciones entre los Chankas y los otros grupos; así como identificar (de haber existido varios grupos) cual fue el área donde se desarrollaron los Chankas y cuál fue el área preferimos utilizar la palabra Chanka, por ser la más utilizada, aunque pensamos que se escribe Chanqa. 
nuclear de la confederación Chanka, esto aunque entendamos que los Chankas se desplazaron por varios departamentos desde Choclococha. Estas preguntas no las vamos a poder responder en este artículo, pues se necesita de investigaciones intensivas con excavaciones que permitan conocer la secuencia estratigráfica. A pesar de ello creemos que los valiosos estudios que profesores y estudiantes de la Universidad Nacional San Cristóbal de Huamanga vienen desarrollando (tanto para sus prácticas pre-profesionales, para su grado de bachiller o para su título profesional), van conduciendo a solucionar esta problemática. Para el desarrollo del presente artículo, vamos a analizar las fuentes etnohistóricas y las evidencias arqueológicas e históricas, a fin de tratar en algo de dar respuestas a nuestras preguntas, aunque estoy seguro que finalizaremos este trabajo con mayor cantidad de interrogantes.

\section{LAS Fuentes ETNOHISTÓRICAS}

La invasión hispana del Tawantinsuyu y la captura del inca Atawallpa en Cajamarca significó el inicio del proceso de desestructuración de la civilización andina. Los soldados españoles iban acompañados de cronistas que iban narrando los acontecimientos y batallas que se daban lugar, así como recibían información referente a algunos pueblos, con el fin de justificar la invasión y la apropiación de las fuerzas productivas con fines mercantilistas y de explotación minera. La mayoría de estos cronistas hablan de los Chankas, en especial sobre la guerra que mantuvieron con los Incas.

Con respecto a las entidades sociopolíticas nacionales andinas (van Dalen; 2012), las crónicas nos muestran, aunque de manera limitada, como se distribuían estas en los valles y territorios de los Andes centro sur. Algunos de estos cronistas corroboran el hecho que los Chankas se desarrollaron en Andahuaylas. José de Acosta en 1590 al narrar los episodios como el Inca Pachacuteq llegó al poder luego de la derrota de Inca Urco de parte de los Chankas, quienes provenían del valle de Andahuaylas: "El principio de sus victorias [de Pachacuteq] fue que un hermano mayor suyo, que tenia el senorio en vida de su padre y con su voluntad administraba la guerra, fue desbaratado en una batalla que tuvo con los Changas, que es la nacion que poseia el valle de Andaguaylas, que esta obra de treinta o cuarenta leguas del Cuzco, camino de Lima, y asi desbaratado, se retiro con poca gente". (Acosta; 1954: libro sexto, capítulo XXI).

De igual manera el cronista Juan de Betanzos, uno de los más fidedignos y creíbles, por haberse casado con una hermana de Atahualpa y haber recibido la información de manera directa de los quipucamayoq, señalaba que en los alrededores del Cusco, en unas 60 leguas a la redonda (que equivale a 360 Kilómetros), existían más de 200 entidades sociopolíticas, con sus respectivos gobernantes autónomos: "En el tiempo deste Viracocha Inga habia mas de doscientos Senores caciques de pueblos y provincias, cincuenta y sesenta leguas en la redondez desta ciudad del Cuzco, los cuales se intitulaban y nombraban en sus tierras y pueblos Capac Inga, que quiere decir Senores e reyes ...." (Betanzos; 2010: capítulo VI).

Miguel Cabello de Valboa es otro cronista que cuenta sobre la existencia de los Chankas, señalando que luego de su derrota con los cusqueños se regresaron al valle de Andahuaylas de donde eran originarios:

“.... y vencidos y perdidos los forasteros Changas, se pusieron en conocida huiday se bolvieron avergonzados a su valle de Andaguayllas dejando presos a sus Capitanes, y caciques Tomayguaraca y Astoguaraca a los quales (despues de muy escarnecidos) mando el general Yngayupangui matar ante si, y de sus cabezas hizo vasos para beber. (....). y ansi tomando consigo un buen egercito reforzado de valerosos caudillos, tomo el camino para Anda Guaillas, en busca delos arrogantes Changas, y por el camino yva haciendo tantos y tan crueles castigos, que sembro terror, y espanto en toda la tierra y fue notado (....) Avida victoria con los Changas paso a la tierra de los Soras, los quales (confiados en su multitud) se hicieron fuertes en la fortaleza de Chalco Marca y dandoles muy continuas baterias y asalto, los desvelo 
y canso y al cabo binieron a sus manos. Con estas victorias pudo (con poca dificultad) ayuntar a ellas la que huvo de los Lucanas, y de otras naciones a quien las nuevas de las crueldades de esta gente dejaua pasmadas, y sin sangre ni aliento." (Cabello; 1951: tercera parte, capítulo 14 y 15).

De igual manera el gran cronista, el Inca Garcilaso de la Vega narra cómo llegó a ver a los Chankas viviendo en el valle de Andahuaylas: "De la provincia de Andabailas, y lo que se contiene en ella hasta llegar al valle de Xaquixaguana cuando yo entre en esta provincia era senor della un indio principal llamado Basco, $y$ los naturales han por nombre chancas. Andan vestidos con mantas y camisetas de lana". (Garcilaso; 1976: libro tercero, capítulo XII). Más adelante describe las características sociales de estas poblaciones Chankas, las cuales estaban relacionadas con otros grupos como los Hancohuallu, Utunsulla, Uramarca y Vilca, llegando a establecerse en la provincia de Andahuaylas:

"De Curampa fue a la gran provincia llamada Antahuailla, cuyos moradores se extienden a una mano y otra del camino real, por espacio de diez y seis o diez y siete leguas. Es gente rica y muy belicosa. Esta nacion se llama Chanca (....).

Debajo de este apellido Chanca se encierran otras muchas naciones, como son Hancohuallu, Utunsulla, Uramarca, Uillca y otras, las cuales se jactan descender de diversos padres, unas de una fuente, otras de una laguna, otras de un collado muy alto; y cada nacion tenia por dios a los que tenia por padre, y le ofrecia sacrificios. Los antepasados de aquellas naciones vinieron de lejas tierras y conquistaron muchas provincias, hasta llegar donde entonces estaban, que es la provincia Antahuailla" (Garcilaso; 1976: libro tercero, capítulo XV).

Felipe Guamán Poma de Ayala enumera varias entidades nacionales de los Andes que conformaban el Tawantinsuyu, entre estas, grupos ubicados entre los actuales departamentos de Ayacucho y Apurìmac como: los Chankas, Soras, Lucanas, Collana Aymara, Laramate, Antamarkas, entre otros; casi todos divididos en el Tawantinsuyu en dos parcialidades (Hanan y Lurin): "De las dichas ciudades y villas, aldeas, de estos reinos y provincias, y parcialidades, ayllos de indios de este Novo Reino (....) Hatun Lucana, Chaupi Lucana, Laramate, Antamarca, Apcara, Omapacha, Cichuc ayllu, Zanco Uanca, Chuschiaymara, Putica, Circamarca, Quilla, Tanquiua, Hanan Sora, Lurin Sora, Challco, Hanan Changa, Lurin Changa, Hanan quichiua, Lurin Quichiua, Collana aymara." (Guamán Poma; 1980). Más adelante señala que estas naciones fueron conquistadas por el Inca Yahuar Huaca: "Y dejo conquistado [Yahuar Huaca Inga], demas que su padre que conquisto Condesuyos, Parinacochas, Pomatambo, Lucanas, Andamarcas, Soras, y la provincia de los Changas". (Ibid).

En 1586 Monzón realiza una visita al repartimiento de Atunsora, actual provincia de Sucre, en el cual la población local señaló que eran de la nación Sora y eran enemigos de los Chankas y que su territorio limitaba con Andahuaylas y Andamarca:

"En el pueblo de San Bartolome de Atunsora, de la encomienda de Hernando Palomino, jurisdiccion de la ciudad de Guamanga (....)

Y traian guerra con los indios Chancas, provincia de Andaguaylas, que son sus mas cercanos vecinos, y que peleaban con hondas y con unas piedras horadadas con unos palos atravesados en ellas, que llaman en su lengua collotas. (....)

y tiene por comarca la provincia de Andaguailas, rio en medio, y por otra parte, al Poniente, tiene la provincia de los Antamarcas".

(Monzón; 1965a: 222)

Martín de Murúa, otro cronista del siglo XVI en su obra: "Historia general del Perú, origen y descendencia de los Incas", señala también que los Chankas eran de la provincia de Andahuaylas y que luego 
que el Inca Pachacuteq (Yupanqui) los derrotó en el Cusco, los persiguió y derrotó totalmente en Andahuaylas, conquistando luego a los Soras y Lucanas, quienes eran vecinos de los Chankas:

“... y los Chancas de la prouincia de Anda Huaylas salieron en aquella ocassion de sus tierras y antes hauian venido hasta cerca del Cuzco, en tiempo de Viracocha Ynga - y este Ynga Yupanqui, viendo el dano que hacian en su tierra, salio a ellos y les dio dos batallas - la vna en Quialtichi, detras de Yabira, y la otra en Sichupampa, detras de Sacsa Huana (sic), y en entrambos los bencio e hizo boluer huyendo a sus tierras de Anda Huaylas. (....)

Fue siguiendo Ynga Yupanqui a los Chancas hasta Anda Huaylas y en diuersas vezes que peleo con ellos los vencio y sugeto y mato todas las cabezas senores y Curacas que le parecio que podian tratar de reuelarse, por asegurar con esto su senorio, y de nueuo puso Curacas y senores de su mano, hijos de los que quedauan muertos en las batallas y de los que prendio y mato en los primeros encuentros, como esta dicho./ Acauado esto, passo adelante, conquistando a los Soras y Lucanas, que estan inmediatos a los Chancas, y los Soras, por ser mas gente, se hicieron fuertes en la fortaleza de Chalcomaca y alli por fuerza de armas los vencio y sugeto," (Murúa; 1962: capítulo XIX).

Líneas más adelante, señala Murúa que la ciudad de Huamanga se llamó primeramente como Pocra, seguramente por ser este el grupo sociopolítico que ocupaba estos territorios al momento de la llegada del Tawantinsuyu, reiterando además nuevamente que el fértil valle de Andahuaylas era la tierra de los Chankas: "Llamauase [la ciudad de Huamanga] en su primera fundacion Pocra. Desta ciudad se sube a la ciudad del Cuzco, y se pasa por el muy fertil valle Andaguailas, yndios chancas de la corona real, y de alli al balle de Amanca...." (Murúa; 1962: capítulo XIX).

El Licenciado Juan Polo de Ondegardo en 1571 afirma también, al igual que los anteriores cronistas, que los Chankas eran de Andahuaylas: "Este mismo tiempo, poco mas o menos, debe haber que ellos empecaron a señorear y conquistar en aquellas comarcas del Cuzco; y segun parece por sus registros algunas veces fueron desbaratados, y aunque Andaguaylas esta treinta leguas del Cuzco, que es la provincia de los Chancas, no lo sujetaron ni metieron debajo de su dominio hasta el tiempo de Pachacuti Ynga Yupanqui ynga" (Polo; 1917: Tomo IV, capítulo: RELACIÓN DE LOS FUNDAMENTOS ACERCA DEL NOTABLE DAÑO QUE RESULTA DE NO GUARDAR A LOS INDIOS SUS FUEROS).

Por último Pedro Sarmiento de Gamboa, también describe que los Chankas eran originarios o naturales de Andahuaylas, teniendo por autoridades o sinchis a Uscovilca y Ancovilca, llegaron al Cusco tras haber hecho guerras y saqueos en los alrededores del valle de Huamanga:

“.... sucedio que los Chancas de Andaguayllas, treinta leguas del Cuzco, vinieron sobre el Cuzco, como en la vida del Inga Yupangui se dira. (....)

Treinta leguas del Cuzco al poniente es una provincia llamada Andaguayllas, cuyos naturales se llaman Chancas. En esta provincia hubo dos cinches, ladrones y crueles tiranos, llamados Uscouilca y Ancouilca, que viniendo robando con ciertas companas de ladrones desde los terminos de Guamanga, habian venido asentar al valle de Andaguayllas y alli habian hecho dos parcialidades." (Sarmiento de Gamboa; 1965: segunda parte, capítulo XXV).

Con respecto a las costumbres, tradiciones y características sociales de los Chankas, Cieza de León describe su forma de vida de la siguiente manera:

"Preguntandoles yo a estos chancas que sentian de si propios y donde tuvo principio su origen, cuenta otra nineria o novela como los de Jauja, y es, que dicen que sus padres remanecieron y salieron por un palude pequeno, llamado Soclococha, desde donde conquistaron hasta llegar a una parte que nom- 
bran Chuquibamba, adonde luego hicieron su asiento. Y pasados algunos anos, contendieron con los quichuas, nacion muy antigua, y senores que eran desta provincia de Andabailas, la cual ganaron y quedaron por senores della hasta hoy. Al lago de donde salieron tenian por sagrado, y era su principal templo donde adoraban y sacrificaban. Usaron los entierros como los demas; $y$ asi, creian la inmortalidad del anima, que ellos llaman xongon, que es tambien nombre de corazon. Metian con los senores que enterraban mujeres vivas y algun tesoro y ropa. Tenian sus dias senalados, y aun deben agora tener, para solemnizar sus fiestas, y plazas hechas para sus bailes. (....) Todos los mas traen cabellos largos entrenzados menudamente, puestos unos cordones de lana que les vienen a caer por debajo de la barba. Las casas son de piedra. En el comedio de la provincia habia grandes aposentos y depositos para los senores. Antiguamente hubo muchos indios en esta provincia de Andabailas, y la guerra los ha opacado como a los demas deste reino. Es muy larga y poseen gran numero de ganado domestico, y en sus terminos no tiene cuenta lo que hay montes. Y es bien bastecida de mantenimientos y dase trigo, y por los valles calientes hay muchos arboles de fruta". (Cieza; 1986: capítulo XC).

Sobre la guerra que dieron los Chankas a los Quichuas que vivían en Apurímac (Cotabambas y Andahuaylas), algunos cronistas mencionan que los Chankas le arrebataron por la guerra una parte de Andahuaylas y Abancay, que se encontraban en su poder, por lo cual los Quichuas luego se aliaron a los Incas para derrotar a los Chankas, sus eternos enemigos:

"Y (afirman) los indios que en este tiempo eran senores de la provincia que llamaban Andaguailas los Quichuas y que de junto a un lago que habia por nombre Choclococha salieron cantidad de gente con dos capitanes llamados Guaraca y Uasco, los cuales vinieron conquistando por donde venian, hasta que llegaron a la provincia dicha; y como los moradores della supieron su venida, se pusieron a punto de guerra animandose los unos a los otros, diciendo que seria justo dar la muerte a los que habian venido contra ellos; y asi, saliendo por una puerta que va a salir hacia los Aymaraes, los Chancas con sus capitanes venian acercandose a ellos, de manera que se juntaron y tuvieron algunas platicas los unos con los otros y, sin quedar avenidos, se dio la batalla entre ellos; que, cierto segun la fama pregona, fue renida y la victoria estuvo dudosa; mas, al fin, los Quichuas fueron vencidos y tratados cruelmente, matando a todos los que podian a las manos haber, sin perdonar a los ninos tiernos, ni a los inutiles viejos, tomando a sus mujeres por mancebas. $Y$, hechos otros danos, se hicieron senores de aquella provincia y la poseyeron como hoy dia la mandan sus descendientes. Y esto helo contado porque adelante se ha de hacer mucha mencion de estos Chancas." (Cieza; 1553b: capítulo XXXVII).

Por su parte Garcilaso señala: "Los antepasados de aquellas naciones vinieron de lejas tierras y conquistaron muchas provincias, hasta llegar donde entonces estaban, que es la provincia Antahuailla, la cual ganaron por fuerza de armas, y echaron sus antiguos moradores fuera de ella y arrinconaron y estrecharon a los indios Quechuas en sus provincias, ganandoles muchas tierras; sujetaronles a que les diesen tributos; tratabanlos con tirania; hicieron otras cosas famosas de que hoy se premian sus descendientes." (Garcilaso; 1976: libro tercero, capítulo XV). De igual manera Garcilaso afirma sobre la anexión de los Quichuas al Tawantinsuyu:

"El Inca general y sus maestres de campo entraron en una provincia llamada Cotapampa; hallaron al senor de ella acompanado de un pariente suyo, senor de otra provincia que se dice Cotanera, ambas de la nacion llamada Quechua. Los caciques, sabiendo que el Inca enviaba ejercito a sus tierras, se habian juntado para recibirle muy de su grado por Rey y senor, porque habia muchos dias que lo deseaban, y asi salieron acompanados de mucha gente y con bailes y cantares, y recibieron al Inca Auqui Titu, y, con muestras de mucho contento y alegria, le dijeron: "Seas bien venido Inca Apu (que es general) a darnos nuevo ser y nueva calidad con hacernos criados y vasallos del hijo del Sol, por lo cual te adoramos como a hermano suyo, y te hacemos saber por cosa muy cierta que si no vinieras tan presto a reducirnos al servicio del Inca, estabamos determinados de ir al ano venidero al Cuzco a entregarnos al Rey y suplicarle 
mandara admitirnos debajo de su Imperio, porque la fama de las hazanas y maravillas de estos hijos del Sol, hechas en paz y en guerra, nos tienen tan aficionados y deseosos de servirles y ser sus vasallos que cada dia se nos hacia un ano. Tambien lo deseabamos por vernos libres de las tiranias y crueldades que las naciones Chanca y Hancohuallu y otras, sus comarcanas, nos hacen de muchos anos atras, desde el tiempo de nuestros abuelos y antecesores, que a ellos y a nosotros nos han ganado muchas tierras, y nos hacen grandes sinrazones y nos traen muy oprimidos; por lo cual deseabamos el imperio de los Incas, por vernos libres de tiranos". (Ibid, capítulo XII).

Con respecto a los Soras, Jiménez de la Espada publica la visita a Hatun Soras que realizara Luis de Monzón en 1586, quien realizó numerosas preguntas, referidas a la forma de vida de sus pueblos. Aunque la información es tardía, algunas características sociales fueron mantenidas desde antes de la anexión de estos territorios al Tawantinsuyu:

"Hay en este repartimiento y provincia tres parcialidades, la una se llama Anansoras, que quiere decir los Soras de arriba, y otra que se dice Lurinsora |Lurin Sora o Hurin Soral, que quiere decir los Soras de abajo, y la tercera se llaman los Chalcos, cuy a nominacion es a diferencia de las otras dos ya dichas. (....) esta tierra es fria y seca, tolerable, y en ella llueve a los tiempos y meses que en Espana (....) en este repartimiento $y$ provincia de los Soras hay dos mill y cuatrocientos y cincuenta y nueve indios tributarios conforme a la visita y tasa que se hizo por mandado del senor don Francisco de Toledo (....) y son de mediana estatura y dociles y inclinados a sus labranzas y sementeras y ganados; y al presente hablan la lengua general quichua del Inga. Tienen otra lengua natural suya, que es la lengua aymara, y tienen otras lenguas en que se hablan y se entienden, que se llama hahuasimi, que quiere decir lengua fuera de la general. (....) y que servian al inga de correos y traerle en unas andas, y en este trabajo y ocupacion pagaban el tributo; y lo que en general adoraban es un cerro nevado que esta en lo alto de la sierra desta provincia, que se llama Caruaraso, que quiere decir nieve amarilla, y por la mayor parte adoraban al sol y a la luna y estrellas, aguas y piedras (....). El habito y traje antiguo de los naturales Soras es el que al presente traen, que es una camiseta y una manta de lana de la tierra; y traen por calzado unas suelas de cuero de carnero de la tierra, y otros las traen de cabuya, cierta yerba de que hacen sogas; y en la cabeza traen unos cordones de lana parda y blanca de la tierra, que es la insignia que el inga les dio para diferenciarlos de otras provincias y conocerlos; y las mujeres traen una manta a raiz de las carnes, presa sobre los hombros con unos topos de metal y cenida con una faja que llaman chumbi, que es de lana de carneros de la tierra, con muchas vueltas, y el calzado el propio de los varones, y traen sobre la manta otra mas pequena cubierta de la propia lana. (....) Y los mantenimientos de que usaban son los que de presente usan, que son maiz y papas y ocas y quinua y frisoles y tauris, que son atramusis de Castilla, y yuyos, y yerbas cocidas y crudas y carnes de sus ganados (....) toda la provincia de los Soras esta cercada con dos rios caudalosos. El uno se dice el rio de Sora, que nace de la puna alta desta provincia y se junta con el rio grande de Vilcas; y el otro se llama el rio de Apcara (....) en las quebradas de los pueblos desta provincia hay algunos arboles que se llaman alisos y otros que se llaman molles; sirven los alisos de madera para labrar sus casas, son en poca cantidad y no muy crecidos (....) en esta provincia hay ganados domesticos, que son carneros de la tierra, que sirven de carga, y otros que llaman pacos, mas pequenos, que tienen lana, de que hacen el vestido; son casi de la propia hechura y genero y buenos de comer a todo genero de gente; y deste ganado hay en razonable cantidad; hay otros ganados bravos que se llaman guanacos y bicunas, de la misma facion, dispusicion y grandeza que los carneros de la tierra; hay venados y tarugas, que es lo mesmo que venados con cuernos (....) hay perdices de pies pardos, chicas y grandes; hay aguilas y halcones; $y$ los indios tienen en sus casas unos animalejos pequenos como conejos pequenos, que los llaman cuis; hay vizcachas, que son como conejos pardos, salvo que tienen colas largas; crianse entre las penas. Hay pajaros de diferentes generos y colores. (....) los indios tinen lo azul con papas, y lo verde y amarillo con molle y chilca. (....) los pueblos desta provincia se proveen de sal de un cerro que esta cinco leguas de la ciudad de Guamanga y 
del pueblo que llaman de La Sal, donde nace un manantial de agua salobre que, cociendola en ollas, sacan unos panes de sal morena y en poca cantidad; y proveense de aji, genero de especia, de los Yungas, que es tierra caliente, de los mas cercanos, que sera a veinte y cinco leguas desta provincia; $y$ del vestido se proveen de la lana de sus ganados. (....) las casas desta provincia son pequenas y bajas, hechas a dos aguas, y otras redondas de piedra y barro, sin cal, cubiertas con paja, de rustica proporcion. (....) los naturales desta provincia tratan y contratan en coca y carneros de la tierra (....)" (Monzón; 1965: 223-224).

De igual manera en 1586 el gobernador Pedro Carbajal realizó la descripción de la provincia de Vilcashuamán:

"Es gente, por la mayor, parte, de mediana dispusicion y medianamente limpios. Son de rostros y faiciones muy semejantes a los espanoles, aunque en el color difieren, porque este le tienen un poco moreno. Usan un solo vestido de ordinario, de lana de la tierra o algodon; ponense unas camisetas, que llaman unco, sin mangas ni cuello, que les llega poco mas de a la rodilla, y encima se ponen una manta cuadrada, que llaman yacolla |llacolla|, que les cubre desde los hombros hasta la espinilla; y en la cabeza se ponen unos que llaman llautos o pillos, que son a manera de cordones y otros a manera de cintas anchas, con que se dan ciertas vueltas a la cabeza; y estos son de diferentes colores, conforme en cada provincia y nacion se usa, por los cuales se distinguen los unos de los otros. Traen unos como zarag-Iruelles que llaman guara, que les llega a medio muslo; y en los pies traen un cierto calzado antiguo, a manera de abarcas, hecho de cuero de los carneros de la tierra, con sus ataderos de lana negra. (....) Hay en esta provincia de las semillas de la tierra: maiz, papas, ocas, collucos, quinua, porotos, altramuces camotes yucas; de las de Espana, hay trigo y cebada, y demas desto hay garbanzos. Hay en esta provincia ganado de la tierra, que son carneros a manera de camellos, aunque son mas pequenos, de los cuales se saca la lana de que se visten los naturales; $y$ estos carneros son domesticos, que les sirven de llevar las cargas, y demas desto, la carne dellos comen los indios y es de buen sabor. Hay otros animales silvestres, casi a manera de los mismos carneros, que se llaman guanacos y vicunas, cuya carne se come; y hay ciervos, y otros que llaman bizcachas, que son a manera de conejos, ecepto que tienen cola; $y$ otros animalejos a manera de ratones grandes, que llaman cuhies, unos domesticos y otros silvestres. (....) Tiene esta provincia al Oriente el rio grande de Vilcas y los pueblos de Coripa y Mayomarca; al Poniente tiene la provincia de los indios Lucanas; al Septentrion tiene la ciudad de Guamanga, y al Mediodia tiene la provincia de los indios Soras."

(Carbajal; 1965: 209)

Ese mismo año también se realizó la descripción del Repartimiento de Hatun Rucana y Laramati, también realizado por Luis de Monzón:

“.... en este repartimiento hay dos ayllos, que son Ananrucana y Lurinrucana; Atunrucana se derivo porque en este dicho pueblo de Atunrucana se juntaban en tiempo de los Incas todas las dichas dos parcialidades a tratar cosas que les convenia, y en estas dos parcialidades se comprenden todos los indios deste repartimiento de Atunrucana, y Ananrucana, que quiere decir primero, y Lurin Lucana (asi), el postrero; y asi, el cacique principal deste repartimiento manda y gobierna los indios de Ananrucana, y la segunda persona gobierna y manda los indios de Lurinrucana. (....)Y en estas punas y tierra fria y quebradas donde los indios tienen sus pueblos, hay manantiales y arroyos que bajan de la puna, que es la tierra fria, y esta tierra no es falta de aguas, es abundosa de pastos para los ganados de los indios y es competente para los mantenimientos de los indios, que ni les falta ni les sobra para proveer a otros. (....) [existen] dos mil y ochocientos y once indios tributarios, y por todos, chicos y grandes, quince mil y doscientas y sesenta y dos animas; y que en tiempo de Topa Inca hubo muchos mas indios que ahora; y que en tiempo de Guayna Capac, hubo menos indios que en tiempo de 
Topa Inca; (....), que hubo mas indios en tiempo de Topa Inca porque el Topa Inca daba a los caciques y principales muchas mujeres, y por esta causa entienden que en el tiempo de Topa Inca multiplicaron mucho. (....) Son los indios deste repartimiento de mediana estatura y algunos de mas y menos, de buenas faiciones y de buenos entendimientos y inclinados a saber leer y escribir y saber las cosas de los espanoles, y viven en sus pueblos, teniendo igualmente tierras los indios tributarios, porque a estos se les reparten y todos las labran y cultivan, ansi los principales como los demas, y mujeres y indios todos se ocupan en sus labranzas; y ansi mesmo los mas dellos tienen ganado de la tierra en los altos, que se dice puna (....) Y en este repartimiento hay muchas diferencias de lenguas, porque casi cada cacique tiene su lengua, aunque todos hablan y se entienden en la del Inga; y a las lenguas diferentes de la del Inga en que se hablan y entienden, la llaman hahuasimi (....) que antes que senoreasen los Ingas esta tierra, en tiempo de su gentilidad, en cada pueblo habia su senor, que ellos llamaban curaca, al cual no le daban mas tributo que comida y lena y servicio y labrarles sus tierras; y que el principal de esta provincia se llamaba Condor Curi, que quiere decir buitre de oro, y este era el principal dice en lengua espanola. Otro principal se llamaba Yanquilla, que no saben lo que dice en lengua espanola. Otro pincipal dicen que hubo que se llamo Caxa Angasi, que quiere decir espina azul; y que el Inga primero que conocieron se llamo Topa Inga Yupangui, y luego sucedio Guaina Capac, (....)Y los indios deste repartimiento de Atunrucana se ocupaban en traer por toda esta tierra al Inga en andas; y que no pagaban otro tributo; y que el Inga les mando que adorasen al sol y a la luna; y que antes que el Inga los senorease, adoraban cerros y quebradas senaladas, y que sacrificaban corderos de la tierra y cuies, que son como conejos pequenos; y que asimesmo adoraban en tiempo de su gentilidad las lagunas que hay en la tierra fria, que se dice puna, y que la ceniza de los corderos y cuies que sacrificaban, la dejaban donde quemaban estos corderos y cuies; y que en esta tierra y repartimiento obedecian a un curaca que el Inga senalo que se llamaba Guancar Illa (....) que antes que los Ingas senoreasen esta tierra, traian guerra y diferencias los unos con los otros sobre las tierras de sementeras y pastos de sus ganados, y que peleaban con guaracas, que son hondas, y con otros que llaman champis, que es como maza de armas; y que despues que el Inga los sujeto, no tuvieron guerra entre si; y que el vestido y traje que traen ahora traian en tiempo del Inga, que es una camiseta de lana hasta la rodilla y una manta que les servia de capa; y traen panetes, que ellos llaman guara, aunque ahora los mas usan de zarag-|ruelles pequenos; traen en la cabeza unas que llaman guaracas, que son de lana, tejidas, cuadradas, tan gordas como el dedo menor de la mano, blancas y coloradas y negras, cada guaraca de su color, que es la senal que el Inga les dio para conocerlos sin preguntar de que provincia eran. Traen en los pies unas suelas de cuero con unas ataduras de lana con que las atan en el empeine y talon del pie, que llaman ojotas; y tambien las hacen de cabuya, que es la joha del maguey, que es un arbol, como esta dicho, que cubren con el sus casas en lugar de madera. Y las mujeres traen una manta cuadrada junto a las carnes, asida con unos alfileres grandes, que ellos llaman topos, encima de los hombros, y fajadas por el ombligo con unas fajas que llaman manachumbi; y encima desta se refajan con otra faja de cinco a seis brazas de largo, tejida de muchos colores, que le llaman chumbi; y encima desto traen otra manta de lana menor que la llaman lliquilla, que les sirve de manto y la ponen por los hombros y les llega a la rodilla; traenla asida en el pecho con otro topo pequeno, y en la cabeza les cine con una bincha ancha de dos dedos, tejida de lana de colores, y no traen otro tocado; y el calzado que traen es el propio que los indios. Y lo propio comen ahora que antiguamente, que es maiz, papas y ocas y frisoles y altramuces y carnes de la tierra (....) y ansi mesmo comen muchas yerbas, que ellos llaman yuyos, cocidas y crudas; y asi mesmo comen las ovas de los rios cocidas con aji. (....) en esta provincia se sustentan de 
maiz y papas, que son como turmas de tierra, y otras que dicen ocas y frisoles y atramuces (asi), y quinua y otras yerbas que comen cocidas y crudas, que comen con aji y sal, que es su ordinaria especia. (....) que todas las casas son bajas y pequenas, y en lugar de clabazon, atan con sogas la madera y la paja con que las cubren, que la paja es a manera de esparto; y las casas son de cinco o seis brazas de largo, y otras son menores, a dos aguas; son echas de piedra tosca y barro sin cal y enlucidas con la misma tierra,"

(Monzón; 1965b: 230)

Finalmente, ese mismo año Luis de Monzón realizó la descripción del repartimiento de Rukana Antamarka:

“... tiene por nombre Rucanas Antamarcas, y tiene origen esta denominacion de Antamarca, de un pueblo llamado asi, adonde estaban poblados en tiempo de su gentilidad un ayllo o parcialidad que ahora se dice asimismo Antamarcas, y estan reducidos en otro pueblo que se dice La Vera Cruz de Cauana; y puesto que en este nombre de Antamarcas Rucanas se comprehenden todos los indios deste repartimiento y provincia, hay en ella cuatro ayllos o parcialidades, que se nombran asi: Antamarca, Apcara, Omapacha, Huchucayllo. Antamarca quiere decir pueblo de cobre, y no tienen noticia los indios por que se haya llamado asi; Rucana quiere decir dedo; Apcara quiere decir fortaleza, y por ser el pueblo cercado de pared y foso, se quedo con este nombre, por ser algo fuerte, y al presente esta reducido en este sitio, como abajo se dira; Omapacha, que es otra parcialidad, quiere decir, en lengua antigua de los propios indios particular, tierra de aguas, por haber copia de manantiales; Huchucayllo quiere decir una parcialidad que se junto de muchas pequenas. (,...) toda la mas tierra desta provincia es llana, alta, rasa, fria, que en la lengua de los indios se dice puna (....) se visitaron, siendo visorrey don Francisco de Toledo, dos mill y ochenta y un indios tributarios, y por todos, chicos y grandes, once mill y setecientas animas. (....) Hay en este repartimiento mucha diferencia de lenguas; porque, los de la parcialidad de Antamarca tienen una de por si antiquisima, y los Apcaraes otra, y otra los Omapachas, otra los Huchucayllos, y estas lenguas no tienen nombre cada una de por si, (....) antes que senoreasen los Ingas esta tierra, en tiempo de su gentilidad, en cada pueblo habia su senor, que ellos llaman curaca, y tenian guerra entre si los de un pueblo con los de otros pueblos; y no tienen ahora noticia de los nombres de los senores que en estos pueblos habia cuando el Inga los sujeto. Y el primer Inga de que tienen noticia se decia Tupa Inca Yupangui (....) y ansimesmo adoraban cerros altos, los que caian en tierra de la parcialidad de cada uno, teniendo en estos cerros sus guacas y adoratorios, que eran unos como carneros de la tierra hechos de piedra, y otros carnerillos hechos de barro; y en estos adoratorios mataban corderos de la tierra y los sacrifican, y cuies (....) Ansimismo adoraban algunas lagunas que estan en la tierra alta que hemos dicho puna, y otros manantiales, ofreciendoles maiz, coca y otras cosas de comida. (....) Y en cada pueblo tenian un cercado con sus casas dentro, donde estaban recogidas las mujeres escogidas para el Inga, y destas daba a los que queria por mujeres; y tenian sus tierras de labor senaladas para ellas, y los principales de los pueblos tenian cuidado de sembrarlas y cogerlas (....) antes que los Ingas senoreasen esta tierra, traian guerras los indios de unos pueblos con otros (....) Dicen los indios viejos, que tienen noticia de sus antepasados, de oidas, que en tiempos antiquisimos, antes que los Ingas los senoreasen, vino a esta tierra otra gente a quien llamaron viracochas [podrían ser los Wary], y no mucha cantidad, y que a estos los seguian los indios viniendo tras ellos oyendo su palabra, y dicen ahora los indios que debian de ser santos. A estos les hacian caminos, que hoy dia son vistos, tan anchos como una calle y de una parte y de otra paredes bajas, y en las dormidas les hacian casas que hasta hoy 
hay memoria dellas, y para esta gente dicen que se hizo este pueblo dicho; y algunos indios se acuerdan de haber visto en este pueblo antiguo algunas sepulturas con huesos, hechas de losas de piedra cuadradas y enlucidas por de dentro con tierra blanca, y al presente no parece hueso ni calavera destos. (....)"

(Monzón; 1965c: 241)

Algunos viajeros alemanes, ingleses y franceses que entre los siglos XVIII y XIX pasaron por el Perú describieron algunos sitios arqueológicos de nuestro estudio. Clemente Markham (1923: 119) señala que los Chankas estaban conformados por los Hancohuallus, Quiñuallos, Utusullas, Urumarcas, Vilcas, Tacmanas, Pocras, Iquichanos y Morochucos.

\section{Las Evidencias Arqueológicas: Análisis de las InVestigaciones}

Los primeros momentos de las investigaciones sobre la arqueología Chanka estuvo marcado por trabajos realizados por la clase intelectual regional ayacuchana. Entre estos cabe mencionar trabajos como los de Alberto Arca Parró (1923) quién publicó en la Revista Inca el trabajo: “¿Dónde vivían los Chancas?". Víctor Navarro del Águila (1936) publicó: “Monografías sobre Pocras, Wankas y Chankas”, sustentando tres años después la tesis titulada: "Las tribus de Anchu Wallock". Pío Max Medina (1936) publicó la obra: "Estudio sobre los Pocras. Lizardo Guillén (1946) sustenta su tesis: Algunos aspectos de la historia y arqueología de los Chancas". Hugo Pesce (1942) publica la obra: "Relación somera de algunas ruinas precolombinas de la provincia Chanca de Andahuaylas".

El primer arqueólogo en realizar excavaciones científicas en el departamento de Ayacucho fue Julio C. Tello en 1942, con su equipo de investigación: Toribio Mejía Xesspe, Julio Espejo Núñez, Cirilo Huapaya Manco, Pedro Rojas Ponce, Hernán Ponce Sánchez, Manuel Chávez Ballón y Lizardo Guillén. Las excavaciones desarrolladas en el sitio de Wari Huakaurara permitió que los investigadores definan dos periodos de ocupación a partir de la evidencia cerámica y arquitectónica: "La Kollawa (representada por su típica alfarería que parece ser la más antigua) y la Chanka o sub Chanka (representada por su típica alfarería que parece ser posterior). No se encuentra algún vestigio Inka." (Tello; 2014: 66). Más adelante al describir las excavaciones en la llamada primera necrópolis (primer mausoleo) refieren haber encontrado tres tipos de fragmentos de alfarería, entre estos: "1) del tipo Chanka o sub Chanka en la superficie, el mismo que se halla regado por todo el área de las ruinas.” (Ibid: 81). El 14 de julio, el Dr. Tello disertó una conferencia en la Municipalidad de Huamanga, donde entre otros puntos explicó sobre la arqueología de los Chankas, desconocida, sobre los sitios del Chankas - Mayo o Pukará, con su gran centro en Antamarca (Ibid: 390). En Vilcashuamán exploraron el sitio de Karacha Marca, a 2 Kms de Vilcas, donde hallaron cuevas con gran cantidad de cráneos trepanados (Ibid: 396). Posteriormente, entre noviembre de 1945 y marzo de 1946 Tello encarga a Pablo carrera, Genaro farfán y Marino Gonzáles la exploración de las cuencas de los ríos pampas y Apurímac (Vivanco; 2014b). Al retornar del Cusco, exploraron algunos sitios arqueológicos de la provincias de Abancay y Aymaraes en Apurímac (Tello; 2016, van Dalen; 2016b).

Lumbreras (1974: 195-223) señala que entre la caída del imperio Wari y la llegada del Tawantinsuyu a la región de Ayacucho, el territorio de Huamanga fue ocupado por los Pocras, quienes en el siglo XVI vivían: "en una condición más bien aldeana que urbana, en casas principalmente redondas y pequeñas, que los centros administrativos o de culto se usaban principalmente para las fiestas" (en base a la cita de Damián de la Bandera; 1557:176-177), con una cerámica no fina y de simple elaboración, con una economía básicamente agrícola, con un perfecto manejo de recursos de diferentes pisos ecológicos, en varios casos de manera no continua. Estos sitios se caracterizan por presentar varios tipos de instrumentos 
de piedra (como el caso de morteros) en asociación con la cerámica y la arquitectura. Aya orqo en las alturas de Waska-ura está conformado por un poblado pequeño de viviendas dispersas con áreas funerarias con chullpas pequeñas de cubiertas en falsa bóveda, asociados a recintos de planta circulares aglutinados en la cima del cerro; presenta entre las chullpas y recintos una cerámica muy tosca, apenas decorada con adornos plásticos o incisiones lineales, de color rojo y pocas formas (platos, tazas y cántaros), abundantes temperantes como mica, pasta porosa y poca dureza; cerámica que ha sido definida como el tipo Arqalla. Además aparece en Aya orqo (y en otros sitios cercanos) otra cerámica de manufactura particular más fina, pintada con motivos lineales en blanco o griss sobre la superficie roja engobada y pulida, con limitadas formas (platos gruesos, tazas, vasos), la cual ha sido denominada como cerámica Aya orqo. En los alrededores de Huamanga se han identificado otros dos tipos cerámicos conocidos como Tanta orqo, pintado en tres colores (blanco, gris o negro y rojo); y el tipo Qachisco, cerámica monócroma, decorada por aplicaciones plásticas, más elaborada que Arqalla y asociada a Tanta orjo.

Entre los asentamientos más grandes descritos por Lumbreras, figura el de Arqalla, ubicado en lo alto del valle de Vinchos, sobre el río Cachi, a casi 4000 metros de altitud, el cual está circundado por una muralla, conteniendo en su interior recintos de planta ovalada (de 6 a 8 metros de diámetro), distribuidos de forma no ordenada y edificados mediante mampostería sin argamasa. Otro sitio descrito es el de Chaupi moqo, al noreste de Arqalla, sobre el sitio de Patarajay, caracterizado por ser un poblado pequeño, con pocas edificaciones. Por debajo de los dos sitios se encuentra el de Pataraqay o Urpaypampa, conformado por una población grande con viviendas circulares (tardías) y otras rectangulares (más tempranas o del Tawantinsuyu). En el valle de Allpamayo está el sitio de Kiruray, ubicado sobre una cresta y conformado por viviendas circulares circundadas por una muralla. Wachwalla es otro sitio cercano al anterior, ubicado en la cresta angosta de un cerro con dispersión de cerámica asociada a corrales. Otros asentamientos contemporáneos y de similares características son los de Silvapata, Qelloqello, Qachisqo, Aukimarka (donde se halló vasijas grandes que cumplían la función de urnas funerarias), todos en el mismo valle. En la zona de Paqcha, en el valle de Cachi, se encontró los sitios de Ayapata, Wari perqa y Ñawpas, el primero conformado por viviendas y chullpas (circulares y rectangulares) con presencia de individuos con deformación craneana de tipo anular oblicua; el segundo asociado a Ayapata; mientras que el tercero (Ñawpas) presenta cerca de 400 viviendas de planta circular de entre 3 y 6 metros de diámetro. Más adelante el autor señala que las evidencias presentan la existencia de una etnia uniforme que podría ser los Chanka, que se extendió desde el Mantaro medio hasta el río Apurímac y Castrovirreyna, limitando al sur con Rukanas y Soras. Casi al final define a los tipos cerámicos como estilos. Sin embargo, la descripción de los sitios tiende en la simplicidad, no concluyendo si se trata de ocupaciones Chanka o Pocra.

Medardo Purizaga (1972) publicó un extenso trabajo sobre: "El estado Regional en Ayacucho", en el cual realiza un balance sobre el estado de la cuestión en torno a la problemática Chanka, definiéndolo como una poderosa confederación ubicada entre los ríos Pachachaca, Pampas y las actuales provincias de Huanta, Huamanga y La Mar; área geográfica donde se encuentra cerámica y arquitectura de características comunes. El autor propone que estos estados regionales surgen luego de la caída de Huari, producida a su vez por las contradicciones entre la ciudad (Huari) y el campesinado, aunado a invasiones de grupos provenientes de Andahuaylas (grupos al parecer Chankas), definidos por Lumbreras (1968: 146) como "bárbaros". Para el autor la cultura que se desarrolla en el valle de Huamanga antes del Tawantinsuyu son los Pocras, aunque el nombre de esta formación sociopolítica ha sido desplazado por el de Chanka; concluyendo que en base a las evidencias arqueológicas existen leves diferenciaciones en la cultura material por lo que habrían existido varias culturas unificadas mediante la confederación Chanka, siendo los Pocras la cultura desarrollada en los alrededores de la 
actual Huamanga. Purizaga divide el territorio del área geográfica Chanka en: Huanta, donde están los sitios de Caballoyuq, Azángaro, Tinyac, Pampachacra, Maynay y Patasucro; Huamanga donde se encuentran los sitios de Arjalla, Patarajay, Chaupi mojo, Urco Huasi, El barrio de la Magdalena, Naupas, entre otros; Hoya del Pampas, con sitios cerca de Vilcashuamán, Villca Chanca, Taclla Rasu, Aya Taqui, Lahui Rasja, Millqa, Ñaupallacta, Llamqaya, Cura Urqu, Auquimarca, Huambalpa, entre otros; y La Mar, con el sitio Chapi. El autor señala que la sociedad Chanka fue eminentemente clasista, con clases privilegiadas (guerreros y sacerdotes) y clases explotadas (campesinos, artesanos y esclavos), con una fuerte interacción entre lo militar y lo religioso. Desarrollaron una serie de técnicas líticas para elaborar artefactos con fines domésticos y de guerra. La cerámica para este periodo está caracterizado por el estilo Arqalla y Pataraqay. Finalmente basándose en Víctor Navarro del Águila, enumera una serie de "tribus" conformantes de la nación Pocra, entre ellos: Huamanga, Quinua, Cachi, Sojos Vinchos, Acos Vinchos y Chiara.

Rogger Ravines (1980: 150-153) en base a fuentes etnohistóricas y de viajeros señala que el territorio Chanka se extendía desde las montañas de Huanta hasta la margen izquierda del río Apurímac, incluyendo toda la cuenca del río Pampas. Este autor describe cuatro importantes estilos alfareros del "territorio Chanka" que pueden ayudar a comprender el fenómeno: El estilo Coras, cerámica tosca, pasta clara con engobe exterior en blanco y decoración pintada en negro, con motivos geométricos (líneas irregulares, manchas, combinaciones de líneas y puntos, líneas onduladas y círculos, distribuidos en las provincias de Acobamba, Huancavelica y Angaraes, llegando incluso hasta Huamanga. El estilo Mantaro, definido por Ramiro Matos (1959), formado por vasijas bícromas sobre fondo engobado blanco y diseños cursivos, o con fondo rojo con motivos geométricos pintados en negro y blanco, distribuida en el valle del Mantaro, entre Junín y Huancavelica. El estilo Huayllirca, identificado por Matos en la provincia de Angaraes, formado por vasijas toscas, semejantes al estilo Arqalla, con decoración pictórica en bandas o manchas en color rojo y a veces decoración plástica. Finalmente presenta el estilo Arqalla en Huamanga, descrito por Lumbreras. Lamentablemente el autor tampoco presenta nuevos datos para la comprensión del fenómeno Chanka.

Duccio Bonavía (1991: 519-521) analiza la distribución espacial de las naciones tardías de la sierra centro sur, identificando a los Quechuas, de buenas relaciones con el Cusco, que abarcaban un extenso territorio desde Cotapampas (Cotabamba, Apurímac) limitando con los Vilcas (Vilcashuamán) y al norte de estos se encontraban los Chankas, quienes hacia los inicios del gobierno de Wiraqocha se enfrentaron con los Quechuas cerca al territorio de los Aymaraes (otro grupo de la actual provincia del mismo nombre), ocupando el territorio de Andahuaylas, para después atacar el Cusco. El autor menciona que es difícil conocer si se trataba de una sola organización política, una confederación de pequeños grupos o un estado; pero que al desaparecer Huari, la cultura cambia de grandes ciudades a pequeños villorrios, desarrollándose un nuevo tipo cerámico con decoración en dos o tres colores: una con motivos cursivos descuidados y otra con motivos geométricos en blanco y negro sobre rojo. El patrón de asentamiento fue en construcciones circulares o rectangulares emplazados en la cima de los cerros y con sistemas variables en función a la topografía del terreno. Discrepa con Lumbreras al señalar que muchos sitios descritos por él, así como el estilo Arqalla, son del Tawantinsuyu y no del Intermedio Tardío. En un trabajo posterior (2009a) Bonavía menciona el sitio de Caballoyuq ubicado en los límites de la ceja de selva, conformado por recintos circulares semi-subterráneas dispuestos en hileras sobre la angosta cima de un cerro. Este autor señala que estos sitios amurallados ubicados en la cima de los cerros y definidos por Lumbreras como Chanka son del Tawantinsuyu, por la gran presencia de cerámica Arqalla. 
Daniel Morales (1992: 500-504) asocia en su “Compendio histórico del Perú", al igual que Ravines (al parecer se basa en él), a los Chankas con los grupos socio políticos y estilos cerámicos de Junín y Huancavelica.

El primer trabajo sistemático que nos permite conocer más a fondo y amplio las características de los Chankas, es el de Enrique González Carré (1992), desarrollado a partir de prospecciones sistemáticas de más de 348 sitios arqueológicos de Ayacucho y de excavaciones en algunos de estos, la mayoría en las alturas de la cuenca del río Pampas. Para González la uniformidad arquitectónica en los asentamientos no indica que haya existido clases sociales diferenciadas, ni una clase gobernante; la jerarquía se circunscribió a grupo de jefes de paz y guerra, sacerdotes, y al grupo de asesores de alta dirección. Las excavaciones desarrolladas en Vilcashuamán (Chaud; 1966: 49, Torres; 1969:14, Cahuas; 1979, Astete; 1982) determinaron una secuencia de 3 capas promedio con dos ocupaciones bien marcadas, una más antigua propiamente Chanka del Intermedio Tardío y otra tardía en que se asocia los materiales Chanka e Inca del Horizonte Tardío. El autor señala que el territorio cultural de los Chanka era desde la provincia de Castrovirreyna, la totalidad del departamento de Ayacucho y parte de Apurímac (hasta la desembocadura del río Pampas al Apurímac).

Los pueblos estaban emplazados en las partes más altas y escarpadas de cerros y colinas de difícil acceso, distribuidos entre los 4000 metros de altura y descendiendo progresivamente hasta los 2000 metros, pero siempre en las partes altas. Cada pueblo tiene entre 200 y 500 edificaciones y se emplazaban sobre terraplenes habilitados para horizontalizar el terreno accidentado, entre las edificaciones hay pequeños pasadizos o senderos de circulación. No hay evidencias de plazas o áreas de reunión, ni santuarios, templos o áreas de culto. Tampoco hay diferencia en el tamaño, materiales constructivos, u ornamentación arquitectónica diferencial.

Numerosos asentamientos se encuentran circundados por una muralla de casi 1.20 metros de ancho. Según la forma y función de los recintos se elaboró la siguiente tipología: 1.- Construcciones circulares, de un diámetro entre 4 y 8 metros, con muros de una altura de 2 metros y entre 0.60 y 0.90 metros de grosor, algunos con piedras de caras planas mampuestas con argamasa y otros simples, sin ventanas, con vanos de acceso de 1.20 metros de ancho y de 0.80 a 1 metro de alto. Algunas de estas edificaciones se encuentran aglutinadas y habrían cumplido la función de viviendas. 2.- Construcciones rectangulares de 12 por 6 metros, distantes de las anteriores, ubicadas por lo general en las partes más escarpadas del cerro, cumpliendo la función de vigilancia y observación o como residencia de guerreros. Los muros son de piedras simples, de 0.90 metros de ancho y 1.85 metros de alto, con uno o dos vanos de acceso de 0.80 metros de alto y 1 metro de ancho. 3.- Construcciones con pozo interior, a manera de depósito, de 3 a 6 metros de diámetro, sin vano de acceso, solo de ventilación. 4.- Estructuras funerarias, ubicadas generalmente en el interior de cuevas o abrigos rocosos, cerrando la boca con muros de protección, colocando al individuo al interior bajo el nivel del piso, envuelto en telas de lana, amarrado con soguillas, en tumbas individuales o múltiples y asociado a vasijas de diferentes tamaños. También tenían osarios en cavidades de 3 a 4 metros de diámetro, circundado por un muro de 2 metros de alto y 0.60 metros de ancho, sin presencia de ofrendas ni orden. Las estructuras funerarias mejor elaboradas son las chullpas, de planta ovalada, de 3 a 4 metros de diámetro, con muros de 2.50 metros de alto y un ancho de 0.70 metros, con vanos de acceso orientados al norte de 1.20 metros de alto, con pequeños ductos de ventilación en los muros y cubierta cónica. En algunos casos hay chullpas rectangulares de esquinas curvas y techo en falsa bóveda. 5.- Construcciones productivas: Se edificó grandes áreas de terrazas agrícolas, así como canales para trasladar agua desde reservorios.

Con respecto a la cerámica, González define los mismos estilos y características identificadas por Lumbreras, agregando las siguientes características: Cerámica Tanta Orqo: Presenta combinaciones 
de colores como blanco sobre rojo, gris sobre rojo, negro y rojo sobre blanco y negro, blanco y rojo sobre rojo; podría representar el abandono progresivo de las tradiciones previas que mantenían relación con Wari y el avance de manifestaciones estilísticas propiamente Chankas. Cerámica Qachisqo: La superficie de los objetos ha sido alisada, presentándose en mayor dispersión en Socos Vinchos, Huanta y Tambo, así como en parte de Huancavelica y en menor proporción en Andahuaylas. La función de esta cerámica pudo ser ceremonial. Cerámica Arqalla, distribuido por todo el territorio Chanka, siendo un elemento diagnóstico para identificar asentamientos Chanka. Cerámica Aya Orqo, de mejor manufactura que los anteriores, de formas relacionadas con las formas de la cerámica Tawantinsuyu, siendo muy escaso en los asentamientos Chanka, hallándose en: Cangallo, Vilcashuamán, Huamanga, Tambo, Parinacochas, y Andahuaylas. Además de la cerámica existe abundante instrumental lítico procedente de sitios Chanka, principalmente instrumentos agrícolas, identificándose: 1.- Productos de lascado: núcleos, lascas, láminas y esquirlas. 2.- Objetos retocados: implementos sobre núcleos como bifaces, unifaces, cepillos sobre núcleo; implementos sobre lascas como lascas retocadas, fragmentos retocados, raederas, raspadores y cuchillos; herramientas agrícolas (azadas, azadones, picos, hachas de mano, macanas y rompeterrones) y armas; herramientas pulidas y retocadas (manos de mortero, manos de metate, hachas pulidas), entre otros.

Sobre la organización de los Chankas, González los define como una nacionalidad compuesta por un conjunto de unidades o grupos étnicos que se integraron a ella, compartiendo vínculos de homogeneidad cultural y relación social, conformándose cada una de ellas como unidades políticas independientes asentadas en una aldea, organizadas en torno a la autoridad de un jefe étnico. Las fuentes documentales hacen referencia que Uscovilca y Ancovilca fueron los fundadores de las parcialidades Chankas, dentro de la dualidad de la nación Chanka. La sociedad Chanka tenía como actividad económica básica la agricultura y ganadería, principalmente de camélidos, aunque también había especialistas como los ceramistas (González; 1992: 82-83).

En un trabajo posterior, González (2007: 103-114) agrega que es posible que los Chankas hayan abandonado la vida urbana en ciudades e invadido Ayacucho imponiendo sus formas de vida propiciando la desaparición de Wary. Posteriormente se organizaron mediante alianzas con otras naciones y etnias que se ubicaban en su territorio en una gran Confederación integrada a nivel de cada pueblo y en señoríos independientes, en la cual cada grupo mantenía su autonomía cultural, pero sometidos políticamente al más poderoso. La unidad de esta confederación se dio por motivos políticos y militares. La nación Chanka estaba integrada, según González, por varias agrupaciones o etnias confederadas por sus elementos similares o comunes y respondían a normas de unificación social y política, con tradiciones y características particulares; citando entre estos grupos a los: Willcas, Uramarcas, Utunsullas, Ancoaillos, Andamarcas, Chilques, Tacmanas, Quiñuales, entre otros. La sociedad Chanka no tuvo una marcada diferenciación social entre sus miembros. El autor contempla incluso la posibilidad que se trate de grupos provenientes de la Amazonía, dejando de lado los mitos sobre el origen en Choclococha; proponiendo más adelante que pudieron ser ellos los que saquearon la ciudad de Wary, o que sus grupos conformantes pudieron existir desde la época Wary y estar como grupos marginales de vida rural.

Lorenzo Huertas (1990) publica un artículo titulado: "Los Chankas: proceso disturbativo en los Andes", en el cual analiza la problemática a partir de los antecedentes de estudio. Luego de hacer un recuento sobre las investigaciones desarrolladas en torno a esta problemática Chanka, propone cinco importantes enunciados:

1.- La etnia Chanka se estableció en Andahuaylas y después de un largo proceso, logró acuñar su sello característico en sus producciones culturales: dioses, templos, casas, menajes, usos, costumbres, etc. 
2.- Las investigaciones arqueológicas de los Chankas - salvo Pesce y Guillén- se realizaron fuera de Andahuaylas. Es importante realizar investigaciones en esta provincia para poder comparar su cerámica con los estilos: Coras, Mantaro, Huayllajirca, Arqalla, Tanta Orqo, Qachisqo y Aya Orqo.

3.- La falta de cerámica suntuaria en la sociedad Chanka se debió al fraccionamiento social producido tras la caída Wary. Se trata de un periodo de los "Aucarunas" o gente guerrera.

4.- Es necesario revisar la propuesta de Martha Anders sobre el modelo cuatripartito, en relación al culto a los cuatro grandes Wamanis del territorio Chanka.

5.- Fue una época fluida y no hay ninguna evidencia que demuestre que existió una confederación que comprendiera los pueblos de Huancavelica, Junín, Ayacucho y Apurímac.

Seguidamente Huertas establece cuatro periodos de desarrollo en la historia Chanka:

1.- Primer periodo: Corresponde a los primeros momentos en que los Chankas emergen al escenario de la historia andina, tras la desestructuración de Wary. Si se sigue la historia mítica, en este periodo se habría dado la migración desde Castrovirreyna a Andahuaylas con su tótem: el puma. A su llegada a Andahuaylas emplazan sus asentamientos en la cima de los cerros con sus viviendas de planta circular.

2.- Segundo periodo: Es un periodo caracterizado por la fricción social. Al llegar a Andahuaylas, entablaron largas batallas contra los vecinos Quichuas. Se estableció un gobierno dual con sus dos parcialidades: Hanan Chanka y Hurin Chanka, con Uscovilca y Ancovilca, respectivamente. Después inician guerra con sus otros vecinos: los Soras. Este periodo culmina con la guerra Chanka - Inca.

3.- Tercer Periodo: Los Chankas aliados de los Incas. Luego de la derrota Chanka se da una alianza con el Tawantinsuyu. En este periodo un grupo Chanka al mando de Ancohuallo escapa con su gente y se interna en la Amazonía Norte (Lamas). Otros grupos Chankas fueron trasladados a diferentes regiones en calidad de mitqmas. La alianza con los Incas significó que el estado Tawantinsuyano respetara las manifestaciones culturales propias Chankas.

4.- Cuarto periodo: Corresponde a la historia Chanka en el primer siglo de dominación hispana, caracterizado por la desestructuración organizacional, encomiendas y reducciones de pueblos.

Huertas concluye este importante trabajo señalando que los procesos disturbativos en los Andes se debió a causas sociales y naturales, en los primeros el desplazamiento social se debe al crecimiento del grupo de poder y la necesidad de mayor excedente. Sobre la existencia de una posible confederación Chanka, señala que no existen documentos que afirmen la existencia de tal confederación; de igual manera la arqueología ha demostrado la existencia de varios estilos cerámicos, lo que correspondería a diferentes grupos. El enfrentamiento entre Chankas e Incas se dio en varios momentos, en el primer y segundo periodo.

Jefrey Gamarra (1995) publicó un interesante trabajo sobre el problema del estado en Ayacucho durante el Intermedio Tardío. El autor comienza haciendo una interesante pregunta, sobre: ¿Cómo se dio la transición desde la caída de Wary hasta el periodo Intermedio Tardío mismo?. Seguidamente pregunta si: ¿las formas de organización estatal continuaron subsistiendo en la época post Wary o Intermedio Tardío en el espacio ayacuchano?. Seguidamente, analiza las propuestas de los diferentes autores para la comprensión del Intermedio Tardío y de la cultura Chanka, analizando las propuestas de Lumbreras, González y Huertas. Coincide con este último que a partir de la revisión de las crónicas, el territorio de los Chankas se limitaba a la cuenca del río Pampas y Andahuaylas. Analiza el término Chanka (entrepierna), concluyendo que este no habría sido el nombre como se conocían e identifica- 
ban estas poblaciones, sino un apelativo impuesto por los incas. También señala que los constantes movimientos poblacionales en el Tawantinsuyu y en los primeros años de invasión hispana no llevan a errores al querer generalizar como Chankas a todos los grupos étnicos tardíos de Ayacucho y Apurímac, en un proceso de "disturbación étnica". Gamarra cuestiona también a Lumbreras sobre el mítico origen Chanka en Choclococha, señalando que estos grupos ya habrían existido como una etnia sometida al imperio Wary, como una población marginal del imperio, con sus asentamientos ubicados en zonas periféricas a las áreas de producción Wary, por lo que al destruirse el imperio Wary siguieron desarrollándose. Bauer (2013) plantea algo parecido a partir de sus investigaciones en Andahuaylas. Para Gamarra, la expansión de los Wary hacia el valle del Pampas y la apropiación de los campos de maíz en las partes bajas del valle obligó a los Chankas a ubicarse en las partes altas con producción de tubérculos, aunque manteniendo algunas relaciones con los Wary; pero al caer el imperio, los Chankas no pudieron reproducir las manifestaciones culturales imperiales debido a su marginalidad, a las dificultades climáticas para conseguir agua para el cultivo de maíz de las partes bajas. Esta situación de marginalidad no permitió a los Chankas reproducir patrones de la vida social y cultural imperial, sino local y parecida a la cerámica utilitaria Wary, por lo que la tradición de cerámica fina Wary no continúa con los Chankas hacia el Intermedio Tardío; además que durante el Horizonte Medio no tenían manejo de la tecnología cerámica ceremonial y suntuosa, monopolizado por el mismo estado desde la ciudad de Huari. Finalmente Gamarra señala que para una mejor comprensión del Intermedio Tardío en Ayacucho es necesario partir del estudio de la estructuración de los espacios sociales en el periodo Wary. Lamentablemente hasta la fecha ningún investigador ha seguido esta línea de investigación propuesta por Gamarra para comprender a los Chankas o a los grupos tardíos de Ayacucho.

El año 2002 Frank Meddens publica el artículo: "La secuencia cultural de la cuenca de Chicha-Soras", en el cual aunque no define claramente las características del Intermedio Tardío y otros periodos en los valles de Chicha Soras (Ayacucho), señala que en el Intermedio Tardío se da un cambio notable a nivel demográfico, así como en la tecnología de los materiales, con asentamientos ubicados en la cima de cerros en áreas de mayor defensa, algunos asociados a murallas como Chiqa Jota y Qasa Marca; con edificios circulares, aunque más pequeños que en el periodo anterior, de entre 4 y 5.2 metros de diámetro; así como estructuras circulares más pequeñas (1.6 metros de diámetro) con fines funerarios (tipo chullpas). Se registraron para este periodo 21 sitios, siendo el más grande el de Auquimarca, a 3.8 Kilómetros del pueblo de Pomacocha, a 4100 metros de altitud y con un área de 12 hectáreas, con más de 1100 recintos circulares, 30 chullpas circulares pequeñas en la cima del cerro y andenes que circundan el sitio. Las paredes internas del sitio presentan enlucido y pachillas entre las juntas, técnica no identificada en otros sitios locales. Los recintos se agrupan de a dos y cuatro, con un patio o espacio abierto central. El autor propone que por la cantidad de corrales existentes Auquimarca cumplía una función administrativa relacionada con el pastoreo de camélidos y la redistribución de productos. Además señala que fue un periodo de tensión, con constantes amenazas de guerra, generándose una dislocación demográfica y pérdida del nivel tecnológico en comparación al Horizonte Medio, aunque los sitios son más grandes que en este periodo. El estilo cerámico identificado para la segunda mitad del Intermedio Tardío es el estilo Soras, se caracteriza por presentar una cerámica de superficie parda amarillenta y oscuro tiznado, por lo general sin decoración, de mala manufactura.

Ismael Pérez, Medardo Purizaga y Freddy León (2007: 151-162) publicaron un interesante trabajo sobre Vilcashuamán en el cual presentan el proceso de anexión de este territorio al Tawantinsuyu, identificando y definiendo las características de los grupos que ocupaban los alrededores de Vilcashuamán, como es el caso de los Soras a quienes definen a partir de la visita de Monzón, que se desarrollaron en los territorios de la actual provincia de Sucre, siendo sus más importantes curacazgos los de Chalcos al norte, Paico al sur y los Soras al centro. Los Soras vestían una camiseta y una manta de 
lana, calzando suelas de cuero de camélido o de cabuya, llevando sobre la cabeza unos cordones de lana parda, mientras que las mujeres vestían una manta sobre los hombros. Por su parte señalan que los Rucanas o Lucanas estaban conformados por dos grandes parcialidades: Los Rucanas Antamarcas y los Hatunrucana Laramati. Los Rucanas Antamarcas, por su parte, se dividían en cuatro grandes grupos: los Rucanas propiamente, los Antamarcas, los Apcara y los Omapachas.

Patrice Lecoq (2007) realizó una prospección en la provincia de La Mar identificando aldeas fortificadas ubicadas en la cima de los cerros con fines estratégicos y control de los terrenos agrícolas, asociados a los estilos cerámicos Chankas. Posteriormente (2008) realizó investigaciones en los alrededores del río Pampas entre Ayacucho y Apurímac, identificando asentamientos con arquitectura circular (Korral Korral, Bombelo, Ajoccasa, Llaqta Pata, Chungui Ccasa), relacionados con los Chankas aunque podrían corresponder a otros grupos locales.

Desde el año 2006 hasta finales de esa década un grupo de arqueólogos han desarrollado investigaciones en la cuenca del río Negromayo en la provincia de Lucanas. Jorge Cámara (2009) realizó investigaciones en el importante asentamiento de Canichi emplazado sobre un promontorio rocoso cerca al pueblo de Carmen Salcedo, en una zona de poca pendiente, el cual está conformado por dos sectores, el primero ubicado en la parte más elevada y con mayor cantidad de estructuras arquitectónicas (cerca de 30 de entre 2.5 y 4.5 metros de diámetro) y dispersión de cerámica. Las unidades arquitectónicas tienen un solo vano de acceso, con muros de 1.80 metros de alto y entre 0.40 y 0.60 metros de ancho, edificados con piedras mampuestas con argamasa, presentando algunos recintos con divisiones internas y con nichos rectangulares; se distribuyen alrededor de patios en número de hasta cinco recintos. Se tiene la presencia de estructuras de planta circular techado en falsa bóveda, de 1.5 a 3 metros de diámetro. En la parte alta del sector hay recintos grandes (de 9 a 12 metros de diámetro) de planta circular, con grandes nichos, al parecer edificado por el Tawantinsuyu. El sector B ubicado en la parte más baja es de menor densidad de edificaciones, con 20 unidades arquitectónicas de planta circular de 2 a 4 metros de diámetro, distribuidos alrededor de patios. El material cerámico asociado a los sectores corresponde desde el Horizonte Medio 3 (estilo Marke) hasta el Tawantinsuyu, incluyendo el estilo Toqsa del Intermedio tardío. Existe además artefactos líticos (batanes, manos de moler y morteros), así como artefactos y desechos de obsidiana. La cerámica identificada difiere de los estilos Chankas. El autor plantea que para el Intermedio Tardío, la población local cambia el patrón de subsistencia basado en el cultivo de maíz a la explotación de productos de altura y ganadería, aprovechando pequeños enclaves en el fondo de los valles.

Sonia Berrocal (2009) realiza la caracterización preliminar de la cerámica tardía de la cuenca baja del río Negromayo en Lucanas a partir de los materiales recuperados de Canichi, Millpo, Willka Qawana y Aya Moqo. Identifica fragmentos para la fase Toqsa, fragmentos con decoración negro sobre rojo, destacando las ollas, platos y cuencos; así como otros tipos que no corresponden a la cerámica Chanka. Manuel Aguirre (2009) realizó también excavaciones en los Andenes de Andamarca, también en la cuenca del río Negromayo, identificando las estrategias constructivas y de cultivo en estos andenes de máxima ocupación durante el Tawantinsuyu.

Danielle Kurin y Enmanuel Gómez (2010) realizaron una investigación bioarqueológica sobre restos humanos tardíos de Andahuaylas (en cuevas y abrigos de Sonhuayo, Mina Cachihuancaray, Chullizana, Masumachay (en San Antonio de Cachi en Andahuaylas) y el sitio de Llatanacu en Ranracancha (en Chincheros) a fin de determinar evidencias de violencia y prácticas culturales para afrontar esta violencia. Los autores señalan que las investigaciones sobre los Chankas se han centrado en el departamento de Ayacucho, no tomando en cuenta a Andahuaylas, y en los pocos casos han tratado de aplicar modelos y esquemas arquitectónicos y cerámicos ayacuchanos. Los datos osteológicos de los res- 
tos óseos de Andahuaylas revelaron una alta frecuencia de traumas, entre ellos la trepanación craneal (hay evidencias de individuos sanados y otros que fallecieron en el acto) que se realizó de tres tipos: por raspado, cortado y taladro, siendo la primera la más común y exitosa. Los individuos analizados son de diferentes edades (desde fetos hasta ancianos), con un $85 \%$ de adultos y $15 \%$ sub-adultos (menores de 16 años), mientras que el 33\% corresponde a individuos de sexo femenino y un $40 \%$ de sexo masculino, no existiendo distinción por sexo en el entierro en cuevas y abrigos, aunque hay algunas donde se enterraba solo hombres y otros solo mujeres. Un 18\% del total presenta patologías como: estrés, parásitos, infecciones virales y bacteriales crónicas, anemia, mal alimentación y traumas por trabajos cotidianos. En algunos sitios como Ccanccayllo toda la población presenta evidencia de patologías, mientras que en otros como Mina eran pocos los que sufrían (10.6\%). El 25\% presenta evidencia de trauma fatal, lo que indica signos de violencia social, aunque había pueblos más violentos y otros más pacíficos. Las trepanaciones se daban solo en adultos y varones, con un $81 \%$ de casos en proceso de sanación. El 62\% de los individuos analizados presenta evidencia de modificación o deformación craneal de tipo fronto-occipital y anular, práctica no relacionada con sexo, edad ni status social, sino con ayllus y grupos étnicos.

Edison Mendoza (2010) realiza la descripción de un conjunto de sitios prospectados en Vilcashuamán, identifica sitios tardíos como Chillhuaqasa (129 estructuras), Corral Pata (187 estructuras), Aya Taki, Chumpecc, Hornuchayuq, Complejo Pillucho, entre otros. Se trata de asentamientos conformados por recintos circulares, rectangulares y ovoides, emplazados sobre terrazas y en algunos casos asociados a canchones. Hay áreas funerarias en chullpas ovaladas o en abrigos rocosos. Para el autor, la entidad sociopolítica tardía que vivía en Vilcashuamán fueron los Chankas, con asentamientos ubicados entre las regiones Suni y Puna, señalando la presencia de sitios ceremoniales para culto a sus divinidades, lo cual va contra la propuesta de González (1992) quien señalaba que no existían asentamientos religiosos.

Juan Carlos Arango (2010) presenta también los resultados de trabajos de prospección arqueológica en la cuenca del río Pampas Vilcanchos, en la provincia de Víctor Fajardo, identificando 9 sitios tardíos: Pachiaqmarka o Sullkalla, Pamparka, Chipta, Pukamarka, Qerapata, Occolla, Cajamarca - Qaqamarka, Condormarka - Cocasmarka y Pukaqaqa. El patrón de asentamiento señala la presencia de pueblos emplazados en las cimas o partes medias de los cerros, con recintos circulares de 6 metros de diámetro en promedio, edificados sobre plataformas, asociados a patios y plazas, identificándose en superficie cerámica de estilos Chanka. Los contextos funerarios se presentan en chullpas de planta ovalada o en el interior de oquedades rocosas. Se identificó al interior de los asentamientos áreas públicas.

Rafael Mallco (2012) reporta las investigaciones arqueológicas desarrolladas en el distrito San Pedro de Larcay, en la provincia de Sucre en Ayacucho. En este trabajo realiza la descripción de los asentamientos más importantes del distrito, identificando sitios de diferentes periodos culturales como Huari, Chanka y Tawantinsuyu. Señala que la época post Huari se caracteriza por la turbulencia política y desplazamiento poblacional, donde los grupos sociales se van a desarrollar independientemente, correspondiendo este territorio a los Soras, teniendo como poblados principales a los de Chiqnajota, Qasamarka, y Taqrapampa; mientras que entre los poblados menores figuran los de Chicha Qasa, Puka Orqo, Llaco, Onqa, Raqayniyuq y Karpani. Los poblados Soras en el valle presentan recintos habitacionales de planta circular, de 5 metros de diámetro en promedio, distribuidos en un patrón aglutinado y sin orden, algunos recintos distribuidos alrededor de patios y otros cerca a acantilados. Puka Orqo está conformado por 37 recintos circulares (de 3 a 5 metros de diámetro) dispersos alrededor de un patio, aunque dos recintos son de gran tamaño por lo que piensa que se trataría de áreas públicas, 
siendo la cerámica identificada en el sitio de los estilos Chicha y Soras. Raqayniyuq también conformado por 65 recintos circulares aglutinados alrededor de patios, asociados a cerámica de estilos Arqalla, Chicha y Soras. Onqa tiene 17 recintos circulares y 30 rectangulares, asociados a montículos de basura con abundante fragmentería cerámica doméstica, así como Chicha, Soras y Tawantinsuyu. El sector B de Qasamarka es del periodo Intermedio Tardío, con más de 50 recintos circulares asociados a patios. Karpani presenta 36 recintos circulares y más de una docena de chullpas. El autor propone que el territorio Soras fue invadido por los Chankas procedentes de Huancavelica, anexándolo a la Confederación Chanka.

Anibal Apaico (2012) presenta las evidencias arqueológicas en la cuenca alta del río Urabamba en Virgen de Cocharcas de Tayacucho, Lucanas. Entre los sitios arqueológicos (ubicados entre los 3900 y 4200 metros de altura) identificados figuran: caseríos, tambos, caminos, cementerios, chullpas aisladas, cámaras funerarias y pinturas rupestres; sitios pertenecientes a los Rukanas y Chankas. Entre los sitios identificados figuran: Taqmasqa Corral, conformado por grandes recintos circulares de 5 a 7 metros de diámetro, asociado a chullpas; Ingawasi Pata, conformado por chullpas y cistas funerarias; Pulpería, formado por 11 recintos rectangulares y 18 circulares; Kunkaylo, formado por una chullpa semicircular; Unchuchucucha, con estructuras funerarias tipo chullpa rectangular al interior de abrigos rocosos; Quintil Cuchu, formado por chullpas semicirculares. El autor da la posibilidad (no afirma enfáticamente) que Tayacucho estuvo ocupado por los Rukanas, con una economía basada en la ganadería, quienes formaban una alianza con los Chankas con fines militares.

William Añanca ha reportado en varios trabajos (Añanca; 2012) las investigaciones desarrolladas en la microcuenca del río Churruwayqu en Chungui, provincia de La Mar. Este trabajo es importante por cuanto es el primero que se desarrolla en esta zona andina amazónica, conocida como "oreja de perro". El autor señala que tras la caída de Wary surgen nuevos pueblos con características socioculturales diferentes, conocidos como Chankas, los cuales se desarrollaron mediante estados y confederaciones de pequeños grupos étnicos, agrupados por intereses comunes de conquista y defensa. El patrón de asentamiento del Intermedio Tardío señala asentamientos ubicados en la cima de los cerros a fin de un mejor aprovechamiento de los terrenos agrícolas, además de producirse un incremento poblacional considerable para este periodo. Añanca registró 11 sitios pertenecientes a este periodo, emplazados en la cima y laderas de los principales cerros, con un solo acceso al sitio, formados por recintos circulares (de 4 a 7 metros de diámetro), emplazados sobre plataformas, dispuestos alrededor de patios o espacios abiertos, con circulación mediante pasadizos entre las edificaciones. Se ha registrado caminos que acceden a estos sitios, así como áreas de control de los caminos que descienden a la selva. Estos asentamientos corresponden a grupos locales tardíos que pertenecían a la confederación Chanka, dedicados a una economía basada en la agricultura. Entre los sitios registrados para este periodo figuran: Muyu Urqu, con un total de 70 recintos circulares asociados a espacios abiertos; Llaqta Pata, con más de 800 recintos circulares; Waychau, con 295 recintos circulares; entre otros.

Sin embargo el investigador que a la fecha ha realizado mayores aportes para el entendimiento de la problemática Chanka y del Intermedio Tardío en Ayacucho, al igual que González Carré, es Cirilo Vivanco Pomacanchari, esto a partir de sus múltiples prospecciones por las diferentes provincias que conforman el departamento de Ayacucho. Son múltiples las publicaciones desarrolladas (Vivanco; 2001, 2002, 2003, 2013, 2014). Uno de estos trabajos (2001) refiere las características de dos importantes sitios tardíos Chanka ubicados en Huancapi (Víctor Fajardo), como son Raqaraqaypata y Ñawpallaqta, ubicados en la cima de cerros: el primero sobre un promontorio cónico con una plaza semicircular en la cima, con recintos circulares (más de 500) emplazados sobre terrazas y asociados a 
patios; el segundo con recintos de planta circular (más de 700) emplazados sobre terrazas y dispuestos en forma alineada y con vanos orientados a patios intermedios y a estrechos pasadizos de circulación, observándose corrales en la parte baja del sitio e identificándose fragmentería cerámica del estilo Arqalla. El autor menciona que el periodo post Wary se caracterizó por la turbulencia política e inestabilidad social. El patrón de asentamiento y arquitectura en Huancapi sufrieron un cambio sustancial por una nueva concepción en el uso del espacio, renunciando a la vida urbana para dar paso a un conglomerado de habitaciones sin aparente orden, con edificaciones aglutinadas y adaptadas a la topografía. Debajo de los asentamientos existen complejos sistemas de andenerías. El patrón funerario en la zona denota el uso de cuevas y abrigos como áreas de entierro múltiple, delimitando al máximo el espacio interno.

En otro trabajo Vivanco (2003) presenta las características de otro poblado Chanka conocido como Pukara o "aldea de Los Gentiles", ubicado en la margen izquierda del río Lucanamarca, provincia de Huancasancos. El asentamiento se emplaza sobre una gran formación natural, con sectores delimitados por murallas y zanjas que circundan conjuntos de recintos circulares aglutinados (más de 1500, con un diámetro de 3 a 6 metros) y asociados a amplios espacios a modo de plazas, con arquitectura a base de piedras canteadas unidas con argamasa, sin presencia de nichos u otros elementos arquitectónicos, solo vanos de acceso. Se aprecia kallankas Tawantinsuyu emplazados sobre recintos circulares. En asociación al sitio se identificó corrales, andenes, manantiales o pukios, canales y caminos. Se ha identificado áreas funerarias al interior de cuevas y oquedades rocosas. La cerámica hallada en el sitio corresponde a los estilos Chankas: Arqalla, Tanta Orqo y Aya Orqo. La presencia de plazas o plazoletas asociadas a las viviendas evidencia una organización de espacios sociales de carácter comunal.

El año 2013 Vivanco publica otro interesante trabajo (Vivanco; 2013) sobre pueblos del Intermedio Tardío en la cuenca del río Pampas y sus afluentes (Qaracha, Sondondo, Torobamba y otros), los cuales presentan características comunes: son sitios complejos, amurallados y con zanjas. Estos sitios están relacionados con la ocupación Chanka del Intermedio Tardío (con arquitectura ovalada) correspondiente a los "grupos locales" Chocorbos, Aimaras, Huancas, Antamarcas, Lucanas, Chankas, Soras, entre otros; así como lo Inca del Horizonte Tardío. Se trata de sitios ubicados en la cima de los cerros, de vida doméstica artesanal y funeraria, de "pukara llaqtakuna". Los sitios están conformados por recintos circulares (edificados en mampostería con argamasa arcillosa en dos hiladas) ubicados sobre un espacio plano y aterrazado, dispuestos de a dos casas en línea paralela, con un corredor o pasaje intermedio; o con 3 a 5 recintos dispuestos alrededor de un promontorio o elevación natural. Las murallas circundantes tienen parapetos y accesos restringidos, asociados a zanjas para dificultar el acceso, con fines puramente defensivos. Para Vivanco los Chanka fueron una confederación de grupos étnicos cuya área nuclear fueron los territorios del actual departamento de Ayacucho, con la cerámica Arqalla de mayor distribución y el Qachisco de característica más local. El autor presenta en otro interesante trabajo (Vivanco; 2014a) la reconstrucción histórica de un mito de fundación de Andamarca - Lucanas, definiendo que los grupos socio políticos que ocuparon parte de esta provincia en el Intermedio tardío fueron los Lucanas y Antamarkas.

Lidio Valdez y Cirilo Vivanco (1994) publicaron el resultado de las investigaciones desarrolladas en la cuenca del río Qaracha que realizaran el año 1988. Estos autores presentan evidencias de una larga ocupación en la zona que abarca desde el Intermedio Temprano hasta el Tawantinsuyu, identificando 16 sitios arqueológicos correspondientes a periodos post Wary o tardíos (6 en la margen derecha y 10 en la margen izquierda), la mayoría ubicados en lugares estratégicos, defensivos y de amplia visibilidad, circundados por murallas defensivas. Los autores señalan que el aspecto defensivo fue importante para este periodo, para defenderse de ataques que eran constantes. Entre los sitios 
identificados figuran: Llamqaya, Cura Orqo, Millqa, Ñawpallaqta, entre otros. Entre el material cerámico recuperado figuran los estilos Arqalla y Aya Orqo.

Otro autor que en los últimos años viene investigando la problemática del Intermedio Tardío en Ayacucho desde la perspectiva de Huanta es Julio Valdez (2003, 2015). Este autor asegura que la caída de Wary trajo consigo un periodo de inestabilidad política, generando que las poblaciones locales ocupen la cima de los cerros con fines defensivos y con el paso de los años formaron parte de la confederación Chanka. Ha identificado numerosos sitios arqueológicos para la provincias de Huanta, Acobamba y Churcampa (Ayacucho y Huancavelica), entre los que figuran: Molinuyoq, sitio amurallado formado por un corralón asociado a recintos circulares y discos líticos grandes; Piruruyoq, también amurallado y con recintos circulares; Toronjana, con más de 300 recintos circulares de 5 a 7 metros de diámetro, con pocos patios asociados y con muralla al lado suroeste; Tunapuquio, con cerca de 15 recintos circulares; Vaca Orqo, con más de 400 recintos circulares de 5 a 8 metros de diámetro, asociados a patios; Torongana, con restos de recintos circulares destruidos; Tinyaq, sitio rodeado de andenes, con recintos circulares, canchones y un reservorio; Ayamachay, cueva con contextos funerarios disturbados; Qoneqorqo, con recintos circulares edificados sobre plataformas; Coras, con terrazas ovaladas y recintos circulares; Arcuilla o Anchacuay, con nichos funerarios elaborados entre afloramientos rocosos; Ayauchco, similar al anterior con nichos funerarios; Unaw; Panco, muy destruido; Ñaupallaqta, con viviendas circulares destruidas, entre otros.

En los últimos años el historiador Jaime Urrutia (2014: 25-37) ha venido publicando trabajos donde presenta algunas características de los pueblos de Ayacucho que fueron sometidos por el Tawantinsuyu, señalando que estos grupos son conocidos genéricamente con el nombre de Chankas, con un patrón de asentamiento de casas redondas dispuestas de manera alveolar, en forma de un "panal de abejas" edificadas en lugares estratégicos de defensa. Señala la existencia de los Ankaras (Huancavelica) con sus dos mitades: Asto y Chacac, en la cuenca del río Chumbao, donde aparece cerámica de estilo Arqalla.

Miriam Salas (1979: 19-21, 1998: tomo I: 33, 2002:60) señala que con la anexión del territorio de Vilcashuamán al Tawantinsuyu y la edificación del nuevo centro administrativo, el Inca dispuso el traslado en calidad de mitqmas de un grupo considerable de Chillques desde el Cusco hacia Vilcashuamán, así como otro grupo de Chillques fueron enviados al Contisuyo. También llegaron grupos de Condes, Pabres, Yauyos, Guandos, Xauxas, Wankas, Guaucas, Chocorbos, Quichuas, Quillas, Aymaraes, Guachos, Quispillactas, Cañaris, Quitos y Quispillasacmarca, a los que se sumaron los originarios Tanquiguas y los Chankas. Cada uno de estos grupos de mitqmas se diferenciaban del otro por llautos o pillos que llevaban sobre sus cabezas. La autora señala que: “....Vilcashuamán, como ciudadela inkaica, ejerció su influencia sobre vastas punas habitadas por los angaraes, chocorbos, lucanas y soras” (Salas; 2002: 60). Para el año 1600, los Hanan y Hurin Chillques, Condes y Pabres, con los demás grupos étnicos de la zona, vivían repartidos en varios pueblos, a veces con un solo grupo o multigrupal, distribuidos en los pueblos de Canaria, Colca, Cayara, Huancapi, Sancos, Ayancas y Huaucas en Lucanas (Ibid: 66). La autora nos muestra como en tiempos del Tawantinsuyu numerosos grupos fueron trasladados en los alrededores de la ciudad de Vilcashuamán e incluso de Huamanga en calidad de mitqmas, cuyos pueblos hasta la actualidad no han sido identificados por la arqueología, siendo al parecer confundidos con los pueblos del Intermedio Tardío locales.

En los últimos dos años han sido publicados trabajos importantes (Bauer, Áraoz y Kellet; 2013 y Espinoza; 2014) que ayudan a dilucidar la problemática Chanka y el problema del Intermedio Tardío en la provincia de Huamanga. Brian Bauer, Miriam Áraoz y Lucas Kellett (2013) publicaron el libro: "Los Chancas. Investigaciones arqueológicas en Andahuaylas (Apurímac, Perú)", en el cual concluyen que el 
territorio ocupado por los Chankas fue el territorio de la actual provincia de Andahuaylas. Los autores desarrollaron trabajos de prospección intensiva en los alrededores de la ciudad de Andahuaylas (en un área de $300 \mathrm{Km}^{2}$ ) identificando 10 tipos de sitios: Unidades domésticas (con dispersión de cerámica, sin arquitectura y en un área menor de 1 ha.), caseríos (con dispersión cerámica en un área entre 0.25 y 1 ha., pero sin arquitectura), aldeas pequeñas (de 1 a 5 has.), aldeas medianas (de 5 a 10 has.), aldeas grandes (de más de 10 has.), torres mortuorias o tumbas en acantilados, corrales, dispersiones líticas, petroglifos y otros. En general, los asentamientos Chanka identificados presentan concentración de estructuras circulares aglutinadas dispuestas en grupos de patios y levantadas sobre terrazas, con arquitectura a base de piedra canteadas y mampuesta con argamasa y con densa dispersión de cerámica, artefactos líticos, restos de fauna y batanes. Las áreas funerarias están conformadas por estructuras tipo chullpas de planta circular concentradas en pequeñas cantidades y ubicadas a mayor altitud en relación a los asentamientos. Los fechados radiocarbónicos obtenidos señalan que los asentamientos Chanka (situados en las cumbres de los cerros) se encuentran ya constituidos desde el 900 d.c., luego de la caída de la presencia Wary en la región. De los casi 200 sitios residenciales identificados, 32 son relativamente grandes (más de 1 ha.), con mayor distribución entre los 3500 y 4000 metros de altitud (suni-puna y cerca al límite superior de cultivo). Achanchi es uno de los más extensos (más de $1 \mathrm{~km}$ de largo) ubicado a 4030 metros de altitud y con más de 300 edificios circulares dispuestos entre pequeños patios y terrazas residenciales, con trinchera defensiva cerca al acceso y con fechados promedio de $1129 \pm 36$ d.c. y $1229 \pm 36$ d.c. Usma es otro asentamiento importante ubicado a 3880 metros de altitud, con recintos circulares asociados a patios, así como chullpas saqueadas, con fechado promedio de 1123+30 d.c. Luisinayoc se ubica a 3716 metros de altitud, cerca al pueblo de Pacucha, con numerosas terrazas de habitación, patios y estructuras circulares, con fechados que abarcan entre $982 \pm 36$ d.c. y $1227 \pm 36$ d.c., sitio muy destruido por una carretera. Otros asentamientos importantes son: Circapata, Waywaka, Cerro Maraypata, Cruzpata, entre otros. Predominan los asentamientos con murallas y trincheras o zanjas con fines defensivos, lo cual es indicador de constantes conflictos. Sin embargo los autores señalan que la ubicación de los asentamientos a alturas considerables obedece no solo a fines defensivos, sino al aprovechamiento de recursos agrícolas y a la actividad de pastoreo, en un periodo caracterizado por constantes sequías, ubicándose cerca a grandes extensiones de pastizales de puna. Entre el 900 y 1000 d.c. se dio un cambio en el patrón de asentamiento, de asentamientos Wary ubicados en el fondo de los valles a asentamientos ubicados en la cima de los cerros. La cerámica local Chanka es de pobre manufactura y hay poca uniformidad o estandarización en sus diseños y formas. Los patrones de asentamiento Chanka sugieren una organización social dual, con Achanchi y Usma como los asentamientos de mayor importancia en cada uno y ubicados a similar altitud. La cerámica Chanka que definen los autores es característica por su pasta color claro y engobe acuoso de naranja o negro, en las caras externa e interna, con decoración descuidada en líneas y diseños mal ejecutados. Se mantiene el patrón de la época Wary con la elaboración de líneas rojas horizontales que circundan el labio de las vasijas para beber. La cerámica Chanka es de pasta tosca con antiplásticos como cuarzo fino, de cocción oxidante (naranja, rosado y griss claro); entre las formas identificadas figuran: tazones, tazones con paredes convergentes, jarras pequeñas, vasijas de almacenaje y tazas. Algunas vasijas presentan la representación de una cara por aplicación en el cuello. Los motivos decorativos son en colores negro y rojo, principalmente lineal.

El recientemente publicado artículo del Dr. Valdemar Espinoza Soriano (2014) sobre la etnia Quinua, nos amplía la visión sobre las sociedades del Intermedio Tardío que ocuparon los alrededores de la actual ciudad de Huamanga. A partir de la revisión de numerosos documentos coloniales, la mayoría inéditos, señala que el término Pocra era el nombre de una chacra del ayllu Guanyacóndor, uno de los ayllus de la etnia Quinua y que erradamente Garcilaso de la Vega lo llamó como nación, de 
donde proviene el error de denominarla como la entidad sociopolítica que ocupó Huamanga antes de la llegada del Tawantinsuyu. De igual manera los Acos que algunos otros investigadores señalan como grupos autóctonos del valle de Huatata, fueron mitqmas traídos por el Tawantinsuyu desde el Cusco (Acomayo). El nombre de Huamanga es colonial y corresponde incluso a otro lugar alejado de la actual ciudad (Quinuacocha), por cuanto la primera fundación de la misma se realizó a tres leguas de distancia de la actual, con el mismo nombre. Guamanga era un paraje que se ubicaba en la parte meridional de Huanta, habitado por mitqmas orejones traídos de Anta (Cusco), al sur de la etnia Parisha o Parija (Huanta); este es un caso muy similar a lo sucedido con la ciudad de Huánuco. El antiguo nombre donde se emplaza la ciudad era Pucaray, la cual tomó el nombre de Huamanga, mientras que la verdadera Huamanga de Huanta tomó el nombre de Huamanguilla para diferenciarla de la ciudad. El territorio comprendido en los alrededores de la actual ciudad de Huamanga, estaba ocupada por numerosos grupos mitqmas y originarios; entre los mitqmas se puede anotar a las docenas de grupos Cañaris, Chachapoyas, Huancas, Nani y Atavillos cerca de Chiara. La etnia que ocupaba los alrededores de la actual Huamanga (y ella misma) antes del Tawantinsuyu era la Quinua, tenía una jurisdicción de legua y media, tenían enclaves en la selva (Mayocmarca y Sintihuaylas) donde cultivaban coca, cerca de enclaves de coca de los Chankas de Andahuaylas. Las familias nucleares y unidades domésticas del señorío Quinua vivían dispersas entre lo bajo y alto de la sierra, más en zonas frías que cálidas, en laderas de cerros sustentándose de la agricultura, ganadería y cacería de especies silvestres. Tenía sus propias salinas, a orillas del río Cachi, cuya población a orillas del río tomó importancia por la actividad comercial con las etnias vecinas. Todos andaban bien vestidos, tenían sus adoratorios y consultaban a sus oráculos, a los que hacían ofrendas y sacrificios. Tenían insignias y tocados para ser reconocidos en el Tawantinuyu. Los Quinuas eran conocidos por sus adivinos, quienes no solo utilizaban coca, sino maíz y animales (arañas, sapos y serpientes). Un ídolo famoso era Tamarico, de grandes poderes entre la población local. Fueron anexados al Tawantinsuyu por el mismo Inca Pachacuteq, luego de numerosas batallas, realizando luego grandes castigos a la población local, algunos ayllus fueron trasladados en calidad de mitqmas, siendo llevados al Cusco para entretener a las panacas a modo de bufones. Hacia el sur de Pucaray establecieron el tambo de Chupas, en cuyos alrededores establecieron a grupos mitqmas de Cauiñas, Acos, Paucarpatas, Cañares y Chachas. Los más numerosos eran los Acos, por lo que el territorio Quinua fue dividido en dos mitades: Quinua Anan Acos y Quinua Lurin Acos. Los Quinuas señalaron en varias visitas ser descendientes de guerreros poderosos que vivieron en la antigua ciudad de Huari. Los Quinuas proveían de maíz a la Llaqta de Vilcashuamán. Con la llegada de Pizarro, los mitqmas Cañares se le aliaron (por lo cual fueron exonerados de las tasas), mientras que el resto de grupos mitqmas y los Quinuas resistieron pasivamente a la destrucción de sus costumbres y tradiciones.

Por último, en los últimos años hemos publicado en diferentes trabajos (van Dalen; 2007, 2009, 2011, 2015, 2016a, 2016b, van Dalen y Grados, 2014, 2016) los resultados de las investigaciones arqueológicas en el distrito de Caraybamba, provincia de Aymaraes, departamento de Apurímac; así como otras desarrolladas en la provincia de Antabamba, investigaciones en las cuales hemos definido las características socio culturales de los aymaraes, entidad sociopolítica que se desarrolló en el ámbito de las actuales provincias de Aymares y Antabamba durante el Intermedio Tardío. Las fuentes etnohistóricas señalan la existencia de una entidad político social conocido como Aymaraes, a raíz del cual se denominó así a la llegada de los españoles a la provincia que ocupó estos territorios, antiguamente ocupado por poblaciones y ayllus de habla aymara. Por su ubicación en una zona estratégica, los aymaraes y por ende los grupos sociales de Caraybamba, aprovechaban diversos recursos, tanto agrícolas, ganaderos y minerales. En las partes altas existían grandes cantidades de ganado, tanto camélidos como guanacos. Vasquez de Espinoza a mediados del siglo XVI señalaba que en la provincia 
de aymaraes, al poniente entre los ríos de Abancay y Apurímac: “....está la provincia de Aymaraes obra de 15 leguas de despoblado, puna tierra fria, y inhabitable, que solo ay en ella algunas cauañas, que llaman miches, donde estan los indios pastores guardando su ganado que es de la tierra, ....... Ay guanacos, vicuñas, pero tambien al presente ay gran cantidad del de Castilla, carneros mermos. La provincia tiene ganado de todas suertes...." (Bonavía; 1996: 308). Los grupos aymaraes se caracterizan por edificar los asentamientos más grandes en zonas altas, en la cima misma o en las crestas media-altas de los cerros más elevados, desde donde se tiene un amplio dominio de la región, con fines defensivos y de control, así como el tener un mejor acceso para la explotación de recursos en la puna y en los valles. En base al proyecto de Catastro arqueológico desarrollado en la cuenca baja del río Caraybamba y el vecino de Colca, es posible señalar la existencia de dos áreas urbanas medianas, constituidos por los sitios político administrativos locales de Pucarqasa (cuenca del río Caraybamba) y Qushku (cuenca del río Colca), cada uno con dos sitios cercanos satélites asociados, que podría indicar diferenciación de segmentos sociales; en el caso de Pucarqasa con los sitios de Lluqi Lluqi y Quishka Pucru, ubicados por debajo de este, y en el caso de Qushku con los sitios de Huaman Marca y Sullacrumi , ubicados por encima de este. Presentan cada sitio más de 200 estructuras, mientras que los sitios satélites un promedio de 120 estructuras. Se da la predominancia de estructuras arquitectónicas de planta ovalada e irregular, sean recintos de función doméstica, administrativa o funeraria. Sin embargo existen algunas Chullpas de planta rectangular y cuadrangular, que como hipótesis podemos plantear, serían más tardías que las circulares o datarían ya del periodo Tahuantinsuyu. Existen estructuras en regular estado de conservación en sitios como Pucarcasa, Qushku, entre otros; las que permiten inferir la altura original de las mismas, las que habrían tenido unos 2.50 metros de alto. En el caso de las Chullpas, estas tienen entre 1.00 y 1.50 metros de altura, pudiendo tener uno o dos niveles. El interior puede contener una o más cámaras. Presenta los muros a base de piedras trabajadas, pudiendo ser bloques o piedras planas. Los paramentos de algunas estructuras están revestidos con arcilla de color amarillo o rojizo, pintado encima de color blanco. En la tercera parte superior de las Chullpas presenta una o dos hileras de ménsulas a modo de voladizos, conformado por piedras planas. La cubierta de las Chullpas son planas (conformadas por lajas entrecruzadas recubiertas de arcilla), o en falsa bóveda. Los vanos son pequeños, de forma cuadrangular, llegando a tener 0.70 metros de altura y $0.50-0.60$ metros de ancho.

Los materiales constructivos de las estructuras de los asentamientos domésticos son básicamente la piedra canteada, obtenida de canteras en cerros adyacentes, y el barro, simple o arcilloso. En algunos casos las piedras denotan cierto grado de tecnificación manual. La técnica constructiva es la mampostería con argamasa. Los muros tienen un ancho de entre 0.50 y 0.70 metros. Las construcciones no presentan muchos elementos arquitectónicos, los vanos son simples, rectangulares, de jamba simple, de hasta 1.80 metros de alto y un ancho entre 0.50 y 0.60 metros. Algunas construcciones presentan nichos pequeños y medianos, de forma cuadrangular. Por efectos climatológicos no es posible precisar si presentaban decoración muraria. Estas estructuras se hallan asociadas a patios de forma irregular y se interconectan mediante pasadizos y calles.

Hemos identificado para el Intermedio Tardío una cerámica local, de naturaleza tosca de pasta color rojo oscuro, la cual estamos denominando como Estilo Caraybamba, que está asociada con la ocupación Aymaraes en la región. Las características de este estilo, en líneas generales, son las siguientes:

Pasta: Pasta color anaranjada, granulosa, con abundantes temperantes como mica y cuarzo. El acabado de superficie es pulido y alisado.

Formas: Entre las formas predominan los cántaros, de tamaño mediano y cuello corto; platos medianos y pequeños; ollas con cuello corto; entre otros. 
Decoración: Algunas vasijas son modeladas con motivos antropomorfos en el cuello de los cántaros. Otras vasijas presentan decoración pictórica con motivos geométricos.

Las poblaciones locales tuvieron mucha consideración en los rituales y práctica funeraria. Es por ello que eligieron áreas funerarias que se encontraban en zonas alejadas de los centros poblados, de difícil acceso, aprovechando predominantemente acantilados, cuevas y abrigos rocosos, tapiando o sellando posteriormente las aberturas con piedras (pircadas con argamasa o simples), ubicándose en zonas elevadas. En el caso de las Chullpas ubicadas en acantilados, estas se edificaron perforando el terreno donde fueron edificadas las Chullpas. Por su parte se apreció en Apu Marka Chullpas edificadas en medio del acantilado, aunque no de tanta pendiente, sobre pequeños aterrazamientos elaborados para mayor horizontalidad del terreno. De igual forma también se ha identificado Chullpas ubicadas en el interior de los centros poblados, como el caso de Pucarqasa, donde se aprecia un conjunto de estructuras en la parte central del asentamiento, encerrado por un recinto ovalado. Se ha identificado dos tipos de entierros, los que presentan estructura funeraria tipo "Chullpa" y los que presentan una estructura simple cavada en la roca o en tierra.

Las unidades de análisis para identificar los contextos funerarios en Caraybamba son los siguientes:

La Estructura: Como se señaló se ha identificado dos tipos de estructuras, las que presentan elementos constructivos y las que están caracterizadas simplemente por presentar una matriz simple ovalada excavada en la roca o la tierra natural.

1.- Las Chullpas se pueden encontrar edificadas sobre el nivel del suelo al aire libre, o en el interior de cuevas y abrigos rocosos; con una altitud de hasta 1.50 metros de alto, hasta 2.00 metros de largo y ancho (aunque en Ararqarqa se han encontrado de hasta 3 metros de largo), con hasta 3 niveles superpuestos. Todas las Chullpas presentan planta rectangular o cuadrangular, aunque en el caso de aquellas ubicadas dentro de cuevas o abrigos rocosos tienen en la fachada una apariencia cuadrangular, pero en la parte posterior se adecuan a la fisonomía del terreno, sin presentar en este lado el paramento respectivo, aprovechando el talud natural del interior de la roca.

Están edificadas íntegramente a base de piedras canteadas, de forma rectangular ligeramente adoquinada, o planas y alargadas, dispuestas en hileras horizontales, unidas entre sí con argamasa arcillosa; con inclusión de pequeñas piedrecillas a modo de pachillas, restos orgánicos como ceniza y fragmentería cerámica. Presentan un vano de acceso pequeño de forma rectangular, de hasta 0.50 o 0.70 metros de altitud, y 0.50 metros de ancho, a desnivel con respecto a la superficie. Los muros tienen un grosor aproximado de entre 0.35 y 0.50 metros.

En cuanto a la cubierta o techumbre de las Chullpas, estas están edificadas a base de lajas que descansan sobre el remate de los muros en una hilera (simple) o en dos hileras (entrecruzadas); y en aquellas ubicadas dentro de cuevas, pueden estar conformadas por el techo natural de la cueva. La cubierta de lajas presenta una gruesa capa de barro arcilloso. En la parte superior de algunas estructuras, presenta hasta tres hileras de lajas que sobresalen a modo de ménsula las cuales se superponen en forma escalonada siendo la hilera de la parte superior la más sobresalida. Algunas presentan solo una de estas hileras, tanto al final del primer como del segundo nivel.

Algunas Chullpas presentan los paramentos con enlucido hecho con arcilla de color amarillo rojizo, identificándose en Apu marka, Ararqarqa y Yanaqaqa Chullpas con los paramentos internos pintados de color blanco y en Uña Huatana de color rojo. En el sitio de Qoricuncachi - Ventanilla se identificó en el interior de una Chullpa fragmentos de hematita y limonita, al parecer utilizada para 
pintar las peredes de la misma. Todas las Chullpas se encuentran disturbadas, producto del intenso huaqueo a que han sido expuestas, presentando abundante osamenta humana, fragmentería textil llana, restos vegetales y orgánicos como tusas de maíz y escasa fragmentería cerámica. Por lo general la mayoría de Chullpas están orientadas hacia el río, posiblemente como costumbre ritual basado en la idiosincrasia religiosa, donde el agua o el río cumplían una función muy importante. La mayor dispersión de las Chullpas se encuentra en el cerro Apu Marka, considerada la paqarina de los antiguos pueblos caraybambinos, en el interior de cuevas y abrigos rocosos. En una de las cuevas (Apu Marka 3) se identificó un conjunto de Chullpas de dos niveles, en los cuales Todos los primeros niveles están orientados al valle; mientras que los del segundo nivel se orientan a uno de los lados laterales de la Chullpa.

2.- Por su parte los contextos funerarios que presentan estructuras simples, están constituidos por fosas o matrices irregulares u ovaladas excavadas en medio de los acantilados rocosos o de tierra, en áreas casi inaccesibles por su elevada pendiente y verticalidad. Se ha podido apreciar tambien contextos funerarios simples en medio de los andenes, intrusitos entre las piedras de los muros de contención. En Chuchulluni, por ejemplo, se aprecia excavación en el farallón rocoso, en cuya concavidad ha sido depositado el individuo sin ningun material asociado, sellándolo luego con piedras canteadas revestidas con barro, dándole un aspecto natural.

La relación entre los contextos funerarios con estructura arquitectónica y sin arquitectura estaría en relación al status social del individuo, relacionado con inversión de fuerza de trabajo en la elaboración de la estructura.

El Individuo: Los contextos funerarios son múltiples, en el cual los individuos están depositados en el interior de las Chullpas, posiblemente en posición fetal o sentados, orientados hacia el río (tal como están las Chullpas). Aquellos contextos con estructuras simples presentarían al individuo en posición extendido o sedente. Cabe señalarse que se identificó entre los restos óseos cráneos con ligera deformación alargada hacia el occipital o ensanchado a la altura de los parietales.

Asociaciones: En base a los materiales observados en el interior de las estructuras se puede deducir que los contextos funerarios presentaban asociaciones de vasijas, soguillas de ichu y otros implementos utilizados en la vida diaria. Los individuos estaban envueltos en varias capas de telas llanas ${ }^{3}$.

Existe una compleja red vial de comunicación que permitía las relaciones e interacciones con Antabamba, mediante el camino de penetración que pasa por la margen derecha, por el medio del sistema de andenerías de Allaqmarca y Chuchulluni, continuando por todos los demás sectores. De igual manera había otros caminos que comunicaban con Chalhuanca y Cotaruse, así como regiones mas lejanas.

Con respecto a las principales actividades económicas, la más importante fue la agricultura, desarrollada en las partes bajas de la cuenca, para lo cual adecuaron y edificaron grandes extensiones de andenerías, excavando en el terreno natural, con el objeto de volver productivas extensas áreas de laderas escarpadas y erosionadas, desarrollando mayormente una agricultura de secano. El tipo de andenes que elaboraron no era el convencional, sino mas simple en su manufactura, excavando la ladera hasta dejar espacios horizontales, en forma escalonada, para luego rellenarla con tierra para el cultivo. En menor porcentaje desarrollaron la agricultura a riego, para lo cual edificaron canales de irrigación.

3. En el interior de las Chullpas se ha encontrado restos de telas llanas que habrían estado envolviendo a los individuos. 
Otra actividad muy desarrollada fue la ganadería, las fuentes etnohistóricas refieren de ello. La puna con sus altipampas inacabables, fue el ambiente natural donde se desarrolló esta actividad a gran escala, prioritariamente de camélidos (llamas y alpacas). Asimismo la artesanía se habría desarrollado al nivel de cada ayllu. Al igual que todos los pueblos del área andina, esta zona habría estado inmersa en el complejo sistema comercial, manteniendo relaciones con las punas de Lucanas y los valles de Abancay.

Para culminar el presente capítulo de este extenso artículo vamos a analizar un importante texto que compila interesantes artículos, que aunque aún no ha sido publicado, la versión en digital ya está circulando, muy importante por abordar investigaciones realizadas en Andahuaylas principalmente. Enmanuel Gómez (2013) al presentar las características de los petroglifos de Andahuaylas hace un balance sobre la secuencia cronológica de esta provincia, señalando para el Intermedio tardío la presencia de los Chankas, apoyándose en la propuesta de la existencia de la Confederación formada con los grupos étnicos vecinos, con objeto de enfrentarse al naciente estado Inca por la hegemonía del dominio territorial, aceptando que aún falta investigar muchos aspectos de su desarrollo, su origen y formas de organización. El autor cuestiona el posible origen mítico de los Chankas en la laguna de Choclococha (como lo señalan las crónicas), citando los resultados de estudios de ADN mitocondrial y estudios bio-geoquímicos con el isótopo de estroncio realizado por Kurin (2012), el cual ha demostrado que los restos óseos de los Chankas de Andahuaylas no comparten la firma isotópica con poblaciones prehispánicas tardías de Huancavelica. El patrón de asentamiento Chanka obedece a las contradicciones sociales y políticas existentes, así como a los cambios climáticos; con un patrón funerario en cuevas y abrigos rocosos antropogénicos con entierros colectivos parcialmente disturbados y con mucha actividad post-deposicional (reutilización), asociados a andenerías (agricultura), corrales (ganadería) y viviendas circulares dispersas. Por su parte Kurin (2013) propone que el origen de los Chankas en Andahuaylas está en relación con el colapso del imperio Wary, surgiendo la sociedad Chanka, la cual se desarrolló entre niveles espectaculares de violencia y con una fuerte competencia entre los diferentes grupos o ayllus Chanka.

\section{Discusión Sobre las Entidades Sociopolíticas Tardías de Ayacucho y Apurímac en Torno a la Problemática Chanka}

Los cronistas tienen información variable sobre el periodo en el que los Chankas fueron anexados al Tawantinsuyu, pues la mayoría señalan que fue durante Pachacuteq cuando recién fueron sometidos por los cusqueños, luego que los Chankas invadieron el valle del Cusco. Otros cronistas señalan que estos acontecimientos se dieron durante el gobierno de Yahuar Huaca y Wiraqocha, mientras que otros pocos señalan que esto se dio durante el gobierno de Inca Roca (Cobo; 1653: libro duodécimo, capítulo IX y Garcilazo; 1609: libro tercero, capítulo XV) y que la ocupación del Cusco en tiempos de Wiraqocha fue una revuelta contra la dominación Cusqueña (Ibid: capítulo X). Las crónicas también hacen referencia que los Chankas eran vecinos de los Quichuas que ocupaban los territorios de Cotabambas: "Y algunos de los orejones del Cuzco afirman que la lengua general que se uso por todas las provincias, que fue la que usaban y hablaban estos Quichoas, los cuales fueron tenidos por sus comarcanos por muy valientes, hasta que los Chancas los destruyeron" (Cieza; 1553b: Capítulo XXXIV). Algunos cronistas incluso dan información que la guerra Chanka-Inca en los confines del Cusco no se dio por un ataque con fines expansionistas de los Chankas, sino por un movimiento de levantamiento de este grupo que ya desde décadas antes se hallaba sojuzgado por los cusqueños y solo buscaban su libertad e independencia.

Las fuentes etnohistóricas también dan cuenta de la existencia de numerosas formaciones sociopolíticas en los actuales territorios de Ayacucho y Apurímac, entre los que se encontraban: Los 
Chankas (actual Andahuaylas), Soras (actual provincia de Sucre), Rukanas en sus dos parcialidades: Antamarkas y Laramates (en la actual provincia de Lucanas), así como Quinuas y Wamangas (actual provincia de Huamanga), Aymaraes (actuales provincias de Aymaraes y Antabamba), Quechuas (provincia de Cotabambas y Grau), Vilcas (actual Vilcashuamán), entre muchos otros. Estos datos etnohistóricos afirman que los Chankas vivieron en los territorios de la actual provincia de Andahuaylas y que ampliaron su territorio luego de la guerra que tuvieron con sus vecinos los Quichuas, a quienes arrebataron zonas contiguas a Andahuaylas, por lo cual estos apoyaron a los Incas en su guerra contra los Chankas.

Sobre el origen de estos Chankas tenemos tres propuestas:

1.- La propuesta emigracionista a partir de la visión mitica que refieren los cronistas que a partir de las leyendas de origen mítico desde la paqarina de la laguna de Choclococha, iniciaron un largo proceso de desplazamiento mediante invasiones para asentarse finalmente en el valle de Andahuaylas, tras su paso por Huancavelica y Ayacucho. Esta propuesta es apoyada por Lumbreras y González.

2.- La propuesta autoctonista regional que señala que a los pueblos que sobrevivieron a la caída del imperio Wary en Ayacucho y Apurímac, no les quedó otra alternativa que ocupar la cima de los cerros. Sin el estado unificador, cada parte del valle, cuenca, sub cuenca y quebrada habría formado una unidad territorial independiente, con cierto grado de relación entre pequeñas entidades políticas (Vivanco; 2013: 319). La unidad cultural Chanka expresa la presencia de grupos y entidades étnicas, algunas de mayor frontera territorial y otras de un ámbito espacial limitado. (Vivanco; 2013: 319).

3.- La propuesta autoctonista local, planteada por Bauer quien señala que los Chankas son autóctonos de Andahuaylas, originándose de la transición del Horizonte Medio al Intermedio Tardío, hacia el 800 d.c. Por las evidencias mostradas en los asentamientos con fechados radiocarbónicos estamos de acuerdo con la tercera propuesta.

Seguidamente creemos que se debe especificar que es una "confederación" para evaluar después si es aplicable o no a la problemática Chanka. Earls y Silverblatt (1978) señalan que la confederación Chanka significó un intento por reconstituir el "imperio Wary”. La confederación es una concepción moderna de las ciencias políticas, pero también geográfica, conformado por una unidad político-territorial compleja a partir de la unión de varias partes soberanas en pos de un bien común. Esta unión (que es voluntaria y no forzada) establecida mediante pactos o tratados, significa la conformación de un gobierno central superior, perdiendo las partes integrantes parte de su soberanía o autonomía. Por lo general las confederaciones se crean a partir de necesidades de pueblos o estados de defenderse ante algún ataque externo, como también de algún desarrollo económico o político; pero cada miembro tiene el derecho de separarse unilateralmente.

Hay dos características básicas que definen a una confederación (Carreras; 2005: 1):

1.- El órgano político superior está conformado por representantes de los estados miembros, buscando representar los intereses de sus partes.

2.- No existe relación jurídica entre la confederación y los ciudadanos, sino con los estados.

Por su parte una "Federación" es un estado formado por la unión de varias unidades territoriales, cada una autogobernada y autolegislada, manteniendo su autonomía. Las partes que componen una federación pueden ser estados (estados federados) regidos por sus propias leyes. Pueden existir federaciones simétricas (cuando todos los estados conformantes tienen el mismo poder) o asimétricas (cuando hay diferenciación de poderes entre los estados miembros). 
De haberse dado algún tipo de confederación entre los Chankas, Soras, Rucanas y otras entidades sociopolíticas habría sido solo para atacar a los Incas que venían ocupando sus territorios, aunque las crónicas no hablan que esta defensa de los actuales Apurímac y Ayacucho haya sido conjunta entre todos los grupos sociopolíticos. Tampoco se menciona si el ataque al Cuzco por parte de los Chankas fue en compañía de sus vecinos. Pero, en el caso de que los Chankas y sus vecinos se hayan unido para hacer frente a los cusqueños, en los casi 40 años que duró el conflicto entre ambos, lo que se habría dado es una alianza y no una confederación, pues las visitas a los Soras y Rucanas demuestran que estos grupos mantuvieron su autonomía e independencia de los Chankas hasta su anexión al Tawantinsuyu, desarrollando sus manifestaciones culturales propias, aunque sojuzgados al poder central cuzqueño. Más aún cuando los Soras manifestaron ser enemigos de los Chankas quienes vivían en Andahuaylas (Monzón; 1965a).

Los indicadores materiales que utilizan los investigadores para definir los asentamientos Chankas son variables y genéricos. Por ejemplo, el caso de la arquitectura de planta ovalada es extendida por todos los Andes durante el Intermedio Tardío, para las regiones altoandinas. En el valle del Mantaro y Pasco o incluso Huánuco, los grupos locales como los Wankas, Chinchaycochas, Taramas, Yaros y Wamalíes tienden a la edificación de recintos de planta ovalada o redonda asociados a patios, similar al patrón arquitectónico tardío existente en Ayacucho y Apurímac, lo mismo que los grupos del altiplano (caso de los Collas o Lupaqas). Algunas entidades socio políticas, caso los Wankas, presentan el patrón tipo alveolar. De igual manera la ubicación de asentamientos en las cumbres circundadas por murallas o muros perimétricos es un patrón extendido por todos los Andes, situación que estaría relacionado al aprovechamiento de productos de diferentes ecosistemas o pisos ecológicos.

Sobre el anterior punto vamos a analizar las características arquitectónicas de otras regiones de los Andes que presentan similitud con la denominada arquitectura Chanka en Ayacucho. Danièle Lavallée y Michèle Julien (1983) definen el patrón de asentamiento Asto (Huancavelica), con asentamientos ubicados en superficies de pendientes fuertes, aprovechando al máximo los espacios disponibles, acondicionándolos para la circulación, agrupación y vida cotidiana de los habitantes. Sobre las superficies centrales más planas se han edificado plazas rodeadas por pequeños muros. Sobre las cumbres de suave pendiente han edificado unidades arquitectónicas contiguas de tipo alveolar, con un total de entre 7 a 12 recintos distribuidos alrededor de un patio; mientras que sobre los flancos más abruptos se han edificado terrazas sobre las cuales han emplazado una o varias unidades alveolares de característica similar a las anteriores. También existe otro tipo arquitectónico que son los "edificios en línea", formados por recintos alineados sin patios, dispuestos en áreas más planas. En las áreas periféricas de los asentamientos existen extensos corrales. La mayoría de estos asentamientos presentan grandes y extendidas murallas. Las edificaciones constan de una pieza única, con un solo vano de acceso y un solo nivel constructivo. Los muros son dobles, formados por piedras grandes sin labrar unidos con o sin argamasa. Este trabajo de Lavallée y Julien es importante por cuanto es el único gran trabajo a mediana escala desarrollado en el ámbito del departamento de Huancavelica. Existen otras pocas publicaciones sobre este departamento que abarcan territorios muy reducidos (Bauer; 2014, Bueno; 1999; 2003, Espinoza Gonzáles; 2010, Espinoza Lozano; 1979, Ravines; 2009, Rosales; 1978, Ruiz; 1977, Ruiz y Farfán; 2000, Serrudo; 2010a; 2010b).

Por su parte, Luis Salcedo (2012) define la arquitectura doméstica de los Wamalíes en Huánuco formada por viviendas de planta circular con hornacinas al interior, de hasta 6 metros de diámetro y dispuestas cercanas entre sí, con un solo acceso que se abre a un patio doméstico individual o una porción de un patio compartido, delimitado por muros bajos y anchos. Los sitios aparecen protegidos por murallas. Para el caso del valle del Mantaro los diferentes autores (Parsons, Hastings y Matos; 2004, 
2013, Mallma; 2004, Onofre; 2009, 2012, Perales; 2011, Navarro; 2013, 2014) han definido la presencia de asentamientos Wankas en la cima de los cerros, con arquitectura formada por recintos circulares dispuestos alrededor de patios y con murallas circundantes como es el caso de los sitios de Tunanmarka y Hatunmarka. Un patrón similar es el que hemos identificado tanto en la provincia de Aymaraes (van Dalen; 2011) como en la misma Amazonía norte en el valle del río Mayo en Moyobamba (van Dalen, Cornejo y Alarcón; 2013). La misma característica tienen los asentamientos Collas del altiplano, ubicados en zonas elevadas y circundado por murallas, conteniendo al interior recintos circulares asociados a patios o espacios abiertos (Arkush; 2012); al igual que los sitios tardíos de la provincia de Yauyos (van Dalen; 2014).

Con respecto a la cerámica de los estilos Chankas como son: Tanta Orqo, Qachisqo, Arqalla y Aya Orqo. De estos cuatro al parecer los dos últimos corresponden al Horizonte Tardío y serían estilos Inca local, probablemente elaborados por grupos de mitqmas, aunque no se les encuentra muy difundidas en los alrededores de Vilcashuamán donde los Incas reasentaron a numerosos grupos de mitqmas. Sobre los dos primeros estilos presentan características comunes en su manufactura, morfología o decoración con otros estilos cerámicos tardíos de los Andes Centrales, como la cerámica Asto (Lavallée y Julien; 1983) o la cerámica tardía de la sierra de Lima (Yauyos, Huarochirí o Atavillos).

Durante el Intermedio Tardío las sociedades tienden a segmentarse y a constituir pequeñas entidades sociopolíticas, desarrollando características culturales similares. Esto lo podemos corroborar, como ya lo hemos señalado líneas arriba, si hacemos un análisis comparativo de lejanas regiones como el altiplano del Titicaca, la región de Ayacucho o la región de Huánuco. Este periodo en la sierra central y sur se caracteriza por la presencia de naciones organizadas en pequeños estados con un sistema religioso de importancia local y regional, estableciéndose en zonas agrestes, en áreas nunca antes ocupadas (Vivanco; 2013: 320). El patrón de asentamiento denota la ubicación de los sitios en zonas elevadas y circundado por murallas o muros perimétricos. Esta ubicación no se debe necesariamente a fines defensivos, sino principalmente al aprovechamiento de productos de diferentes ecosistemas en un periodo de calentamiento climático en el cual el límite superior de cultivo ascendió considerablemente por un proceso de calentamiento global. Augusto Cardish (1980: 23-24) señala que el periodo Horizonte Medio se caracteriza por un descenso de la temperatura con una tendencia más acentuada al frio entre el 500 y el 950 d.c., por lo cual las partes intermedias y bajas de los valles experimentaron un importante aumento demográfico, con grandes desplazamientos de comunidades desde las partes altas, con mayor incidencia de crisis agro-climáticas por descenso de temperaturas, ampliando las áreas agrícolas en las partes bajas y medias, situación que en el caso del Altiplano habría promovido que poblaciones Tiawanaku busquen de manera más intensa el colonizar tierras bajas para el aprovechamiento de productos agrícolas. La primera parte del Intermedio tardío (1000 - 1300 d.C.) estuvo determinado por un acentuado incremento térmico durante casi 300 años (con mayor pico hacia el 1320 d.c.), con un pequeño Optimun climaticum que ha sido identificado en varias partes del mundo, para luego nuevamente descender. Este ascenso de temperatura generó en varios lugares como el Altiplano que los asentamientos que se ubicaban a orillas del lago, asciendan a las partes altas en áreas alejadas al lago, estableciendo pueblos en la cima de los cerros, situación que también se dio en toda el área Andina, estableciendo cultivos hasta la altitud de 4300 metros de altitud. Sin embargo, a partir del año 1320 d.C. (datación con fechados en el Vilcanota) empieza un periodo de enfriamiento en lo que se va a conocer como una "pequeña Edad de Hielo", que con altibajos duró hasta la primera mitad del siglo XIX. Este enfriamiento hizo descender los límites superiores de cultivo, decayendo y abandonándose muchos asentamientos humanos en las partes más altas de los cerros, al igual que sus áreas cultivadas contiguas. Por otra parte, el descenso de la temperatura en la segunda parte del Intermedio Tardío conllevó a pueblos enteros a variar el medio de subsistencia de la agricultura a 
la ganadería. Sin embargo, a pesar de ubicar sus poblados principales en zonas altas (por lo general entre los 3000 y 4000 metros de altura), tenían asentamientos periféricos en otros pisos ecológicos a fin de aprovechar productos de estos ecosistemas, como la coca y frutales en la selva alta, como fue el caso de los Chupachos que al mismo tiempo que pastaban sus rebaños en las punas de Chinchaycocha, explotaban la sal en Yanacachi y cultivaban coca, algodón y ají en la selva del Huallaga y Marañón; sin embargo algunas áreas de archipiélagos culturales como las salinas eran de explotación multiétnica. Un caso similar se daba para los Lupaqas del Altiplano que tenían enclaves en la costa de Arica y Moquegua donde cultivaban algodón y maíz al igual que aprovechaban productos marinos, mientras que tenían otros en la selva de Bolivia de donde aprovechaban la madera y la coca. (Murra; 1972). Los visitadores del siglo XVI a los confines de la ciudad de Guamanga dan referencia que existía considerable ganado conformado por "carneros de tierra" (camélidos), guanacos y vicuñas, en especial en Vilcashuamán (Bonavia; 1996: 306).

Las evidencias etnohistóricas y arqueológicas propuestas por Bauer (2013) revelan que los Chankas son originarios del valle de Andahuaylas y que aquí se desarrollaron. Nosotros estamos de acuerdo con esto. Sin embargo, esto no quiere decir que las caracterizaciones de la sociedad Chanka que se han hecho en el departamento de Ayacucho este mal. Simplemente hay que trasladar esta caracterización para las sociedades locales, caso los Soras, Rucanas, Quinuas, entre otros y darles el sitial que les corresponde. Es necesario identificar en base a los documentos tempranos la territorialidad de los grupos autóctonos del territorio ayacuchano, luego realizar un trabajo prospectivo intensivo para definir las similitudes y diferenciaciones en las características culturales, a fin de determinar patrones de asentamiento.

Sin embargo, las interrogantes iniciales aún se conservan, como en este caso ¿Cómo se originaron los grupos socio-culturales que se desarrollaron en el Intermedio Tardío en la región de Ayacucho? Para ello es importante realizar investigaciones arqueológicas con excavaciones en sitios tipo, en especial en aquellos sitios de cumbres y amurallados, a fin de realizar un detallado análisis arquitectónico y cerámico, así como verificar las asociaciones estratigráficas y de ser posible la obtención de fechados radiocarbónicos que permitan identificar los primeros momentos de ocupación de los asentamientos. Pues, es muy posible, como señala Gamarra (1995) que estos asentamientos hayan estado siendo ocupados desde el Horizonte Medio, formando parte del estado Wary. Sin embargo, otro aspecto que nos va a ayudar a definir la conformación de estos asentamientos y ayllus va a ser definir las causas de la caída y desocupación de la ciudad misma de Huari. Hasta es posible que esta población haya tenido que ver con esto, pues se tiene referencia de haber identificado material cerámico tardío en los estratos superiores de la ciudad, situación que ya había sido referida por Julio C. Tello. Otro aspecto a dilucidar es definir las características sociales y políticas de estas sociedades, definir si se trataba de estados o jefaturas. Pues por las características de los asentamientos y sus manifestaciones culturales se tratarían de jefaturas (Flanery; 1972). Pero, si se trataba de jefaturas, entre estos los Chankas, como es que pudieron llegar al punto de poner en jaque al estado más grande de los Andes y estar a punto de cambiar el destino de la civilización andina si hubieran derrotado a los Incas.

Esperamos que futuras investigaciones intensivas en los departamentos de Ayacucho y Apurímac ayuden a dilucidar más profundamente esta problemática del Intermedio Tardío. 


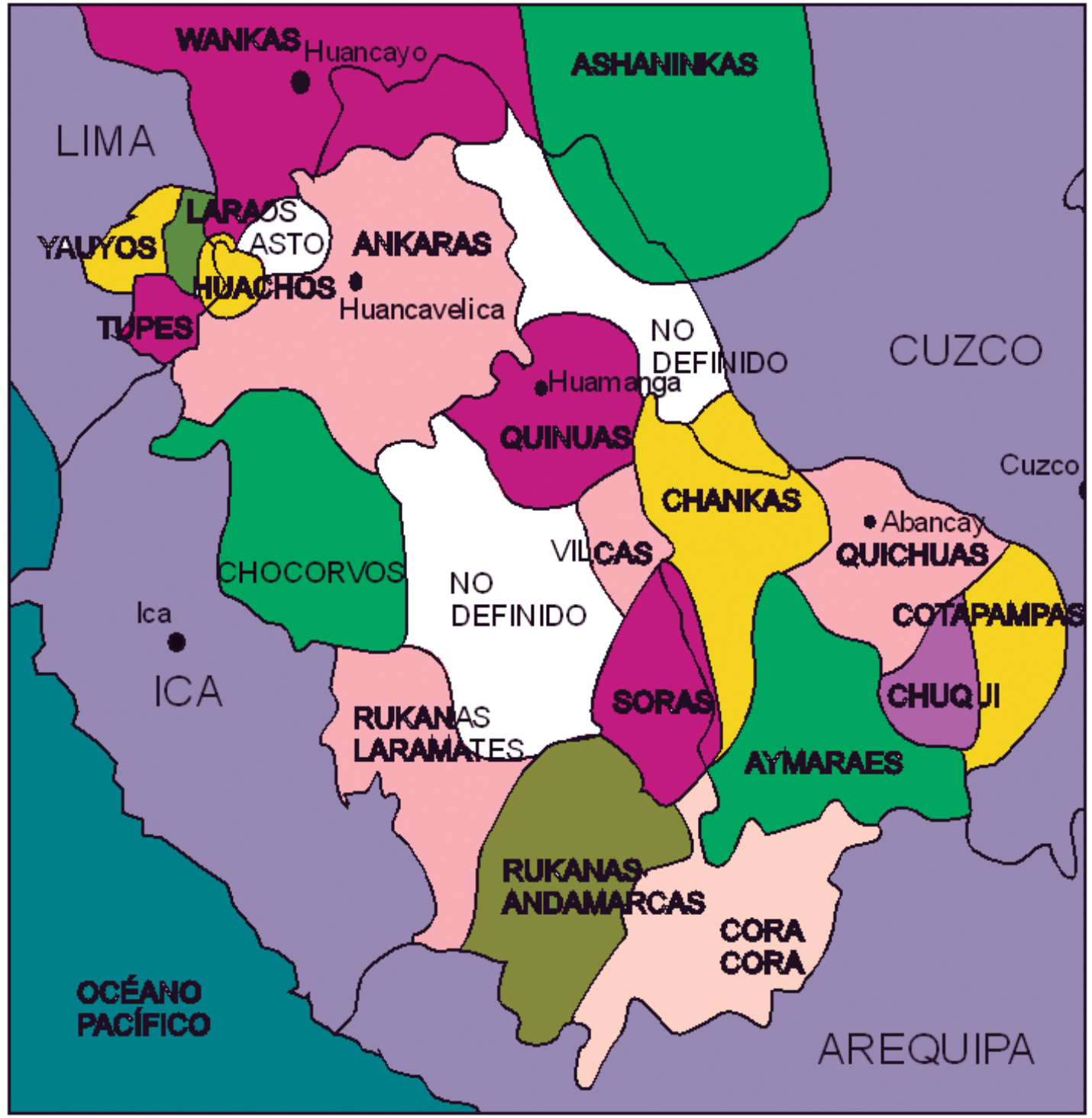

Figura 1: Mapa de la sierra central con la identificación preliminar de las grandes entidades sociopolíticas del Intermedio tardío. 


\section{BiBLIOGRAFÍA}

AcostA, José de

1954 [1590] Historia natural y moral de las Indias. Biblioteca de Autores Españoles, tomo 73. Madrid: Ediciones Atlas, pp. 3-247.

AGUIRRE MORALES, Manuel

2009 "Excavaciones en los andenes de Andamarca, cuenca del río Negromayo, Lucanas, Ayacucho". En: Arqueología y Sociedad N² 20. Museo de Arqueología y Antropología de San Marcos. Lima: Universidad Nacional Mayor de San Marcos, pp. 223-268.

APAICO FLORES, Anibal

2012 "Rimaq Yupikuna: evidencias arqueológicas en el curso superior del río Urabamba, Tayacucho - Lucanas, Ayacucho”. En: Investigaciones sociales $\mathrm{N}^{\circ} 28$. Instituto de Investigaciones histórico sociales. Lima: Facultad de Ciencias Sociales, Universidad Nacional Mayor de San Marcos, pp. 223-232.

AÑANCA ANCHAYHUA, William

2012 “Investigaciones arqueológicas en la microcuenca del río Churruwayqu, Chungui - La Mar". En: Investigaciones sociales $\mathrm{N}^{\circ} 28$. Instituto de Investigaciones histórico sociales. Lima: Facultad de Ciencias Sociales, Universidad Nacional Mayor de San Marcos, pp. 255-270.

ARANGO CLAUDIO, Juan Carlos

2010 "Visión panorámica del desarrollo prehispánico en la cuenca del Pampas Vilcanchos, Fajardo - Ayacucho”. En: Pacha Runa N 1. Revista del Instituto de investigaciones históricas, arqueológicas y antropológicas "Pacha Runa" - IDHAPAR. Huamanga: Universidad Nacional de San Cristóbal de Huamanga, Gobierno Regional de Ayacucho, pp. 163-188.

ARCA PARRO, Alberto

1923 “Dónde vivían los Chancas?” En: Revista Inca. Tomo I, № 4. Lima, pp. 971-974.

ARKUSH, Elizabeth

2012 "Los pukaras y el poder: Los collas en la cuenca septentrional del Titicaca". Arqueología de la cuenca del Titicaca, Perú. Luis Flores y Henry Tantaleán, editores. Lima, pp. 295-320.

ASTETE CANAL, Luis

1982 Conjunto arqueológico: Vilcashuamán. Instituto Nacional de Cultura. Manuscrito inédito. Ayacucho.

BANDERA, Damián de la

1965 [1557] "Relación general de la disposición y calidad de la provincia de Guamanga, llamada San Joan de la Frontera y de la vivienda y costumbres de los naturales de ella - año 1557". Relaciones Geográficas de indias. Perú. Marco Jiménez de la Espada, editor. Tomo I. Biblioteca de autores españoles, № 183. Madrid: Ediciones Atlas, pp. 220-225.

BAUER, Brian; ARAOZ, Miriam; y KELLETT, Lucas

2013 Los Chancas. Investigaciones arqueológicas en Andahuaylas (Apurímac, Perú). Instituto francés de Estudios Andinos, University of Illinois at Chicago, The Institute for New World Archaeology. Lima, $242 \mathrm{pp}$. 
2014 “Un caso de arqueología histórica en Huancavelica: los hornos coloniales de mercurio”. En: Arkinka 18(227), revista de arquitectura, diseño y construcción. Lima, pp. 100-109.

BENAVIDES CALLE, Mario

1976 Yacimientos arqueológicos en Ayacucho. Universidad Nacional San Cristóbal de Huamanga. Huamanga, Manuscrito.

BERROCAL FLORES, Sonia

2009 “Caracterizando la cerámica tardía de la cuenca baja del río Negromayo, (Lucanas - Ayacucho): Aportes preliminares a partir de la cerámica del sitio arqueológico de Canichi”. En: Arqueología y Sociedad. № 20. Museo de Arqueología y Antropología de San Marcos. Lima: Universidad Nacional Mayor de San Marcos, pp. 205-222.

BETANZOS, Juan de

2010 [1551] Suma y narración de los Incas. Universidad Nacional Mayor de San Marcos. Lima: Fondo Editorial de la Facultad de Ciencias Sociales, Unidad de Post Grado, 341 pp.

BONAVÍA, Duccio

1991 Perú Hombre e historia. De los orígenes al siglo XV. Tomo I. Lima: Edubanco, 586 pp.

1996 Los camélidos sudamericanos: una introducción a su estudio. Instituto Francés de Estudios Andinos. Lima: Universidad Peruana Cayetano Heredia, 843 pp.

2009a "Papel de la ceja de selva en el proceso cultural andino". Reinos preincaicos y el imperio Inca. Tercera edición. Lima: Inteligo, pp. 121-132.

2009b "Los orígenes de los Incas y el problema de los Chanca". Reinos preincaicos y el imperio Inca. Tercera edición. Lima: Inteligo, pp. 133-140.

BUENO MENDOZA, Alberto

1999 “Huaytará monumental”. En: Revista Espacio 21(43). Lima, pp. 34-41.

2003 “El Tawantinsuyu en Huaytará, Huancavelica”. En: Investigaciones sociales N 11. Instituto de Investigaciones Sociales. Lima: Universidad Nacional Mayor de San Marcos, pp. 41-56.

CABELLO BALBOA, Miguel

1951 [1586] Miscelánea antártica: una historia del Perú antiguo. Instituto de Etnología, Facultad de Letras, Lima: Universidad Nacional Mayor de San Marcos, tercera parte, pp. 201-483.

CAHUAS MASSA, José

1979 Informe final del proyecto habilitación parcial para el turismo del yacimiento arqueológico de Vilcashuamán. Ayacucho: Instituto Nacional de Cultura.

CÁMARA GUERRERO, Jorge

2009 "Sobre las ocupaciones prehispánicas en la cuenca baja del río Negromayo, (Lucanas - Ayacucho): Una aproximación desde el sitio arqueológico de Canichi”. En: Arqueología y Sociedad. $N^{\circ}$ 20. Museo de Arqueología y Antropología de San Marcos. Lima: Universidad Nacional Mayor de San Marcos, pp. 181-204. 
CARBAJAL, Pedro de

1965 [1586] “Descripción hecha de la provincia de Vilcas Guamán por el ilustre señor Don Pedro de Carabajal, corregidor y justicia mayor della, ante Xpistobal de Gamboa, Escribano de su juzgado, en el ano de 1586". Relaciones Geográficas de indias. Perú. Marco Jiménez de la Espada, editor. Tomo I. Biblioteca de autores españoles, № 183. Ediciones Atlas. Madrid, pp. 205-219.

CARDISH, Augusto

1980 "El fenómeno de las fluctuaciones de los límites superiores del cultivo en los Andes: su importancia”. Relaciones de la sociedad Argentina de Antropología. Tomo XIV, № 1. Buenos Aires, pp. 7-31.

CARRERAS, Francesc de

2005 “Confederación y Estado federal”. En: Revista digital de Ciencias Políticas. Barcelona: Universidad Autónoma de Barcelona, pp. 1-2.

CIEZA DE LEÓN, Pedro

1967 [1553] El señorío de los Incas (Segunda Parte de la Crónica del Perú). Lima: Instituto de Estudios Peruanos, $271 \mathrm{pp}$.

1986 [1553] Crónica del Perú. Primera parte. Colección: clásicos peruanos. Pontificia Universidad Católica del Perú, Academia Nacional de la Historia, Lima, 352 pp.

CHAUD GUTIÉRREZ, Carlos

1966 Investigaciones arqueológicas en Vilcashuamán. Universidad Nacional San Cristóbal de Huamanga. Huamanga.

EARLS, John y SILVERBLATT, Irene

1978 “Ayllus y etnias de la región Pampas - Qaracha: el impacto del imperio incaico”. III Congreso peruano el hombre y la cultura andina: actas y trabajos. Tomo I. Lima, pp. 176-180.

ESPINOZA GONZALES, Rubén

2010 “Una visión de la arqueología de Huancavelica”. Arqueología y desarrollo. Experiencias y posibilidades en el Perú. Trujillo: Ediciones SIAN, pp. 67-78.

ESPINOZA LOZANO, Samuel

1979 Monumentos arqueológicos de Huaytará. Ica, 104 pp.

ESPINOSA SORIANO, Valdemar

1997 Los Incas. Economía, sociedad y estado en la era del Tahuantinsuyo. Lima: Ed. Amaru, 509 pp.

2014 “Etnia Quinua (hoy Huamanga)”. En: Investigaciones Sociales № 33, Revista del Instituto de Investigaciones Histórico Sociales. Facultad de Ciencias Sociales. Lima: Universidad Nacional Mayor de San Marcos, pp. 53-86.

FLANERY, Kent

1972 “The cultural evolution of civilizations". En: Annual review of ecology and systematical. Vol 3. USA, pp. 399-426. 
GAMARRA CARRILLO, Jefrey

1995 "El problema del estado en Ayacucho durante el intermedio tardío: una hipótesis de trabajo”. En: Guamangensis № 1. Universidad Nacional San Cristóbal de Huamanga. Humanga, pp. 48-53.

GARCILASO DE LA VEGA, Inca

1976 [1609] Comentarios reales de los incas. Tomo I. Biblioteca Ayacucho 5. Caracas, Libro I-V. GONZÁLEZ CARRÉ, Enrique

1992 Los señoríos Chankas. Universidad Nacional San Cristóbal de Huamanga. Lima: INDEA, 154 pp.

2007 Historia prehispánica de Ayacucho. Tercera edición. Lima: Lluvia editores, 138 pp.

GUAMÁN POMA DE AYALA, Felipe

1980 [1615] Nueva corónica y buen gobierno. Tomo II, Biblioteca Ayacucho № 76. Caracas, 539 pp.

GUILLÉN, Lizardo

1946 “Algunos aspectos de la historia y arqueología de los Chanca". Tesis de bachiller, Facultad de Letras. Lima: Universidad Nacional Mayor de San Marcos, 90 pp.

HUERTAS VALLEJOS, Lorenzo

1990 “Los Chancas. Proceso disturbativo en los Andes”. En: Historia y cultura. № 20. Lima, pp. 11-48.

KELLETT, Lucas

2008 "High altitude settlement - subsistence dynamics of the Chanka Heartland (Andahuaylas, Perú)". 73rd Annual meeting of the Society for American Archaeology. Vancouver, pp. 2548.

2010 "Chanka settlement ecology: hilltop sites, land use and warfare in late Prehispanic Andahuaylas, Peru". Ph. D. dissertation. Albuquerque: University of New Mexico, 320 pp.

KURIN, Danielle y GÓMEZ CHOQUE, Enmanuel

2010 “Aguerridos Chanca: una aproximación bioarqueológica desde Andahuaylas”. En: Pacha Runa, $\mathrm{N}^{\circ} 1$. Revista del Instituto de investigaciones históricas, arqueológicas y antropológicas "Pacha Runa" - IDHAPAR. Universidad Nacional de San Cristóbal de Huamanga, Gobierno Regional de Ayacucho. Huamanga, pp. 75-98.

LAVALLÉE, Danièle y JULIEN, Michèle

1983 Asto: curacazgo prehispánico de los Andes centrales. Instituto de Estudios Peruanos. Lima, 150 pp.

LECOQ, Patrice

2007 Resultados preliminares de las prospecciones realizadas en la región La Mar de Ayacucho, de junio a agosto de 2007. Manuscrito.

2008 Proyecto arqueológico de Choquek'iraw Chanka 2008. Inédito.

LUMBRERAS SALCEDO, Luis

1959 “Sobre los Chancas". Actas y trabajos del II Congreso Nacional de Historia del Perú. Época prehispánica tomo I. Lima, pp. 211-242. 
1968 “Acerca de la historia del pueblo del Perú". Universidad Nacional Enrique Guzman y Valle. Lima, pp. 129-159.

1974 Las fundaciones de Huamanga. Club Huamanga. Lima, 240 pp.

MALLCO HUARCAYA, Rafael

2012 “Ocupación prehispánica en el área del distrito de San Pedro de Larcay, Sucre, Ayacucho". En: Arqueología y Sociedad № 25. Museo de Arqueología y Antropología de San Marcos. Lima: Universidad Nacional Mayor de San Marcos, pp. 215-258.

MALLMA CORTEZ, Arturo

2004 Introducción a la arqueología e historia de los Xauxa Wankas. Biblioteca Nacional del Perú. Lima, 195 pp.

MAÑARICUA, Pedro

1940 "Primitivos habitantes del departamento de Ayacucho". En: Revista Huamanga. № 32. Huamanga.

MARKHAM, Clements

1923 Las posesiones geográficas de las tribus que formaban el imperio de los Incas. Colección de libros y documentos referentes a la historia del Perú tomo VII. Lima.

MEDDENS, Frank

2001 "La secuencia cultural d ela cuenca del Chicha - Soras". Actas del XII Congreso Peruano del Hombre y la cultura andina tomo II. Universidad Nacional San Cristóbal de Huamanga. Huamanga, pp. 200-210.

MEDDENS, Frank; Mónica, BARNES

1979 The Chicha archaeological project Peru S.A. London, 27 pp.

MEDDENS, Frank; y VIVANCO POMACANCHARI, Cirilo

2002-2005 “The Chanca Confederation: political myth and archaeological reality”. (Confederación Chanca: Mito político y realidad arqueológica, Traducción por Maria Elena Solier). En: Xama № 15-18. Mendoza, pp. 73-99.

MEDINA, Pío Max

1934 “Descubrimientos de tumbas arqueológicas”. En: Boletín de la Sociedad Geográfica de Lima. № 51, vol 1. Lima, pp. 35-45.

1936-38 “Estudios sobre los Pocras”. En: Revista Huamanga № 8-12. Huamanga.

MENDOZA MARTÍNEZ, Edison

2010 "Investigaciones arqueológicas en la margen izquierda de los ríos Yanamayu y Pampas, Vilcashuamán, Ayacucho". En: Pacha Runa, N 1. Revista del Instituto de investigaciones históricas, arqueológicas y antropológicas "Pacha Runa" - IDHAPAR. Universidad Nacional de San Cristóbal de Huamanga, Gobierno Regional de Ayacucho. Huamanga, pp. 123-162.

MONZÓN, Luis de

1965a [1586] "Descripcion de la tierra del repartimiento de Atunsora, encomendado en Hernando Palomino, jurisdicción de la ciudad de Guamanga. Ano de 1586”. Relaciones Geográficas de 
indias. Perú. Marco Jiménez de la Espada, editor. Tomo I. Biblioteca de autores españoles, № 183. Madrid: Ediciones Atlas, pp. 220-225.

1965b [1586] "Descripcion de la tierra del repartimiento de San Francisco de Atun Rucana y Laramati, encomendado en Don Pedro de Córdova, jurisdicción de la ciudad de Guamanga. Ano de 1586". Relaciones Geográficas de indias. Perú. Marco Jiménez de la Espada, editor. Tomo I. Biblioteca de autores españoles, № 183. Madrid: Ediciones Atlas, pp. 226-236.

1965c [1586] "Descripcion de la tierra del repartimiento de Rucanas Antamarcas de la Comarca Real, jurisdicción de la ciudad de Guamanga. Ano de 1586". Relaciones Geográficas de indias. Perú. Marco Jiménez de la Espada, editor. Tomo I. Biblioteca de autores españoles, № 183. Madrid: Ediciones Atlas, pp. 237-248.

MORALES CHOCANO, Daniel

1992 "Historia de la arqueología”. Compendio histórico del Perú. Tomo I. Lima: Editorial Milla Batres, $675 \mathrm{pp}$.

MOROTE BEST, Efraín

1974 “Huamanga entre 1539 y 1547 (Examen del Primer Libro de Cabildo)". Huamanga una larga historia. Lima: CONUP, pp. 39-127.

MURRA, John

1972 "El control vertical de un máximo de pisos ecológicos en la economía de las sociedades andinas”. Visita de la provincia de León de Huánuco en 1562. Tomo II. Huánuco: Universidad Nacional Hermilio Valdizán, pp. 427-476.

MURÚA, Martín de

1962 [1590] Historia general del Perú. Origen y descendencia de los Incas. Tomo I. Colección Joyas Bibliográficas, Biblioteca Americana Vetus. Madrid: Instituto Gonzalo Fernández de Oviedo, 274 pp.

NAVARRO AMARO, Irvin

2013 "Estudio arqueológico sobre el desarrollo productivo de los Guancas y Taramas en los Andes Centrales: nuevas perspectivas”. En: Investigaciones Sociales № 30. Instituto de Investigaciones Histórico Sociales, Facultad de Ciencias Sociales, Lima: Universidad Nacional Mayor de San Marcos, pp. 131-154.

2014 "Estudio arqueológico sobre los Wankas y Taramas. Un nuevo análisis sobre el desarrollo económico y social de estas culturas en los Andes Centrales”. En: Arqueología y Sociedad № 27. Museo de Arqueología y Antropología de San Marcos. Lima: Universidad Nacional Mayor de San Marcos, pp. 153-192.

NAVARRO DEL AGUILA, Víctor

1936 Monografías sobre Pocras, Wankas y Chancas. Lima.

1983 Las tribus de Anchu Wallock. Lima: Ed. Atusparia, 184 pp.

ONOFRE MAYTA, José

2009 “El concepto de nación en la época prehispánica: El caso de la nación Xauxa-Wanka”. En: Kullpi. Investigaciones culturales en la provincia de Huaral y el Norte Chico № 4. Lima, pp. 127-146. 
2012 “La especialización económica en un asentamiento de la nación Xauxa-Wanka”. En: Investigaciones Sociales № 28. Instituto de Investigaciones Histórico Sociales, Facultad de Ciencias Sociales, Universidad Nacional Mayor de San Marcos. Lima, pp. 233-248.

PARRA CARREÑO, Alfredo

1938 “Los Pocras fueron Kechuas o Aymaras?. En: Huamanga N 15. Órgano del centro Cultural Ayacucho. Huamanga, pp. 4-19.

1947 “La historia primitiva de Huamanga". En: Huamanga Nº6. Órgano del centro Cultural Ayacucho. Huamanga, pp. 24-37.

PARSONS, Jeffrey; HASTINGS, Charles; y MATOS, Ramiro

2004 "Reconstruyendo el estado en la sierra central del Perú. La interacción entre pastores y agricultores durante el periodo intermedio tardío en la región de Tarama - Chinchaycocha”. En: Investigaciones Sociales № 12. Instituto de Investigaciones Histórico Sociales, Facultad de Ciencias Sociales. Lima: Universidad Nacional Mayor de San Marcos, pp. 55-98.

2013 Prehispanic settlement Patterns in the Upper Mantaro, Junín, Perú. Vol. 2. Museum of Anthropology, University of Michigan. Michigan: Ann Arbor, 374 pp.

PERALES MUNGIA, Manuel

2011 “Una aproximación al estudio de las sociedades prehispánicas tardías de Ricrán, Jauja. Periodos Intermedio tardío (ca. 900-1470 d.c.) y Horizonte tardío (1470-1533 d.c.)”. Pueblos del Hatun Mayu. Historia, arqueología y antropología en el valle del Mantaro. Lima: José Álvarez, Carlos Hurtado y Manuel Perales, editores, pp. 9-52.

PéREZ CALDERÓN, Ismael; PURIZAGA VEGA, Medardo y LEÓN NINA, Freddy

2007 Vilcashuamán: Paisaje, Historia y tradición. Universidad Nacional San Cristóbal de Huamanga, Oficina de Investigación. Huamanga, 212 pp.

PESCE, Hugo

1942 "Relación somera de algunas ruinas precolombinas de la provincia Chanca de Andahuailas". En: Huaman Puma vol. 2. Cusco.

POLO DE ONDEGARDO, Juan

1917 [1571] Informaciones acerca de la religión y gobierno de los Incas. Segunda parte. Colección de libros y documentos referentes a la Historia del Perú. Serie 1. Tomo IV. Lima: Imprenta y librería Sanmarti y Cia., 204 pp.

PURIZAGA VEGA, Medardo

1972 El estado Regional en Ayacucho (Periodo Intermedio tardío: 1200-1470 d.c.). Huancayo: Ed. Yachayhuasi, $74 \mathrm{pp}$.

RAVINES, Rogger

1980 “Reinos y señoríos locales de los Andes Centrales: 800 - 1476 d.c.”. Historia del Perú. Tomo II. Lima: Editorial Juan Mejía Baca, pp. 93-183.

2009 "Cuatro notas de arqueología”. En: Boletín de Lima, N 156. Lima: Ed. Los Pinos, pp. 5-24. 
ROSALES HUATUCO, Odón

1978 "El templo de Huaytará". III Congreso peruano el hombre y la cultura andina: actas y trabajos. Tomo I. pp. 235-247

ROWE, John H.

1956 “Archaeological explorations in southern Peru, 1954-1955”. En: American antiquity № 22 (2). Pp. 135-150.

1960 Tiempo, estilo y proceso cultural en la arqueología peruana. Instituto de Estudios Andinos. $2^{a}$ ed. Berkeley, 16 pp.

RUIZ ESTRADA, Arturo

1977 Arqueología de la ciudad de Huancavelica. Lima: Servicios de Artes Gráficas, 61 pp.

RUIZ ESTRADA, Arturo y FARFÁN LOBATÓN, Arturo

2000 "Introducción al estudio de la comunidad de Uchkus, Huancavelica". En: Boletín del Museo de Arqueología y Antropología de San Marcos 3(6). Lima: Universidad Nacional Mayor de San Marcos, pp. 2-9.

SALAS, Miriam

1979 De los obrajes de Canaria y Chincheros a las comunidades indígenas de Vilcashuamán, siglo XVI. Sesator. Lima, 183 pp.

1998 Estructura colonial del poder español en el Perú. Huamanga (Ayacucho) a través de sus obrajes, siglos XVI-XVIII. Pontificia Universidad Católica del Perú. Lima, Tomos I, II y anexos.

2002 “Advenedizos y traspuestos: Los mitmaqkuna o mitimaes de Vilcashuamán en su tránsito de los tiempos del Inka al de los señores de los mares”. En: Boletín de Arqueología PUCP № 6. Lima: Pontificia Universidad Católica del Perú, pp. 57-78.

SALCEDO CAMACHO, Luis

2012 Prehistoria Andina II. La ocupación Wamallí en las cuencas de los ríos Lauricocha, Vizcarra y Alto Marañón, Huánuco. ECOTEC. Lima, 164 pp.

SARMIENTO DE GAMBOA, Pedro

1965 [1572] Historia de los Incas (Segunda parte de la Historia General Llamada Indica). Biblioteca de Autores Españoles, tomo 135. Madrid: Ediciones Atlas, pp. 193-279.

SERRUDO TOROBEO, Eberth

2010a “Incahuasi y la ocupación Inka en Huaytará - Huancavelica". En: Arkinka, Revista de arquitectura, diseño y construcción 14(176). Lima, pp. 74-81.

2010 b “El Tampu Real de Inkahuasi y la ocupación Inka en Huaytará". En: Inkallaqta, Revista de investigaciones arqueológicas y etnohistóricas inka 1(1). Lima, pp. 173-193.

TELLO, Julio C.

2014 Cuadernos de Investigación del Archivo Tello. $N^{\circ}$ 12. Expedición al Vilcamayo, 1942. Primera parte: Sierra Central y Cusco. Museo de Arqueología y Antropología, Lima: Universidad Nacional Mayor de San Marcos, 458 pp. 
2016 Cuadernos de Investigación del Archivo Tello N 14. Expedición al Vilcamayo, 1942. Segunda parte: Cusco y Apurímac. Museo de Arqueología y Antropología. Lima: Universidad Nacional Mayor de San Marcos, 481 pp.

TORRES PALOMINO, Jorge

1969 Investigaciones arqueológicas en Pilluchu. Universidad Nacional San Cristobal de Huamanga. Huamanga.

URRUTIA, Jaime

2014 Aquí nada ha pasado. Huamanga, siglos XVI-XX. Instituto de Estudios Peruanos, COMISEDH, Lima: Instituto Francés de Estudios Andinos, 378 pp.

VALDEZ CÁRDENAS, Julio

2003 “Pueblos del Periodo Intermedio tardío”. En: Warpa N 3. Huanta, pp. 3-27.

2015 “Pucullos? en las cuencas de los ríos Warpa, Urubamba y Mantaro, entre Ayacucho y Huancavelica, Perú”. En: Arqueología y Sociedad № 28. Museo de Arqueología y Antropología de San Marcos. Lima: Universidad Nacional Mayor de San Marcos, pp. 199-216.

VALDEZ CÁRDENAS, Lidio

2003 “El estado en Ayacucho durante el Periodo Intermedio tardío”. En: Warpa № 3. Huanta, pp. 28-31.

VALDEZ CÁRDENAS, Lidio y VIVANCO POMACANCHARI, Cirilo

1994 “Arqueología de la cuenca del Qaracha, Ayacucho, Perú”. En: Latin American Antiquity 5(2). Washington D.C., pp. 144-157.

VARGAS FANO, Américo

1939 “La hegemonía Chanca". En: Revista del Museo Nacional № 1. Lima.

VAN DALEN LUNA, Pieter D.

2007 "La recuperación de tecnologías prehispánicas como sistema de recuperación de la identidad nacional”. En: Diario Yachay № 10, julio. Lima, p. 9.

2009 “Andenerías y asentamientos Tardíos en Caraybamba, Apurímac”. En: Investigaciones Sociales № 22, junio, Revista del Instituto de Investigaciones Histórico Sociales. Facultad de Ciencias Sociales. Lima: Universidad Nacional Mayor de San Marcos, pp. 247-270.

2011 Arqueología prehispánica tardía de Caraybamba, Aymaraes, Apurímac. Asentamientos y Andenerías. Universidad Nacional Mayor de San Marcos. Lima, 265 pp.

2012 “Arqueología tardía del valle Chancay-Huaral: Identificando la nación Chancay”. En: Investigaciones sociales 16(28). Instituto de Investigaciones Histórico Sociales. Lima: Universidad Nacional Mayor de San Marcos, pp. 271-283.

2014 "Arqueología de la provincia de Yauyos". Arqueología de las cuencas alto y medio andino del departamento de Lima. Pieter van Dalen, editor. Lima: Universidad Nacional Mayor de San Marcos, pp. 31-81.

2015a “Allwanso, un sitio con pinturas rupestres tardías en Huaquirca, Antabamba, región Apurímac". Actas de ponencias del V Simposio Nacional de Arte Rupestre. Lima: Universidad Nacional Mayor de San Marcos, pp. 77-88. 
2015b “Arqueología de Chocorvo Arma, Huaytará, Huancavelica”. En: Investigaciones Sociales 19(35). Instituto de Investigaciones Histórico Sociales. Lima: Universidad Nacional Mayor de San Marcos, pp. 31-43.

2016a “Arqueología de Abancay: reconociendo a la nación Quichua”. En: El Apurimeño № 175. Abancay, pp. 5.

2016b “Julio C. Tello en Apurímac. El inicio de las investigaciones arqueológicas científicas". En: Cuadernos de Investigación del Archivo Tello N 14. Expedición al Vilcamayo, 1942. Segunda parte: Cusco y Apurímac. Museo de Arqueología y Antropología, Lima: Universidad Nacional Mayor de San Marcos, pp. 31-44.

VAN DALEN Luna, Pieter; CORNEJO CONDEÑA, Cirilo; y ALARCÓN HUIARAC, Gina

2014 “Arqueología de la cuenca media del río mayo, Moyobamba, San Martín”. En: Arqueología y Sociedad, № 26. Museo de Arqueología y Antropología de San Marcos. Lima: Universidad Nacional Mayor de San Marcos, pp. 207-228.

VAN DALEN LUNA, Pieter y GRADOS RODRÍGUEZ, Hans

2014 “El Tawantinsuyu en Allaqmarca, Caraybamba, provincia de Aymaraes, Apurímac". En: Arqueología y Sociedad № 28. Museo de Arqueología y Antropología de San Marcos. Lima: Universidad Nacional Mayor de San Marcos, pp. 205-222.

2016 "Investigaciones arqueológicas y revalorización cultural del sitio de Allaqmarca. Resultados preliminares de la temporada 2013". Actas del I Congreso Nacional de Arqueología Peruana vol. II. Ministerio de Cultura. Lima, pp. 123-138.

\section{VIVANCO POMACANCHARI, Cirilo}

1998 “El poblamiento prehispánico de la cuenca del Pampas y Qaracha”. En: Conchopata N 1. Huamanga: Universidad Nacional San Cristóbal de Huamanga, pp. 163-190.

2001 “Raqaraqaypata y Ñawpallaqta: dos sitios de la época Chanka en el área sur de Ayacucho". Actas del XII Congreso Peruano del Hombre y la cultura andina tomo II. Huamanga: Universidad Nacional San Cristóbal de Huamanga, pp. 271-286.

2003 "Pukara: Un poblado Chanka fortificado en la cuenca superior de Qaracha, Ayacucho". En: Investigaciones en Ciencias Sociales 1(1). Instituto de Investigación de la Facultad de Ciencias Sociales. Huamanga: Universidad Nacional San Cristóbal de Huamanga, pp. 121-142.

2004 "Pukara Llaqtas: Fortalezas en tiempos de Chaqwatas chankas". En: Revista de Relaciones Públicas $\mathrm{N}^{\circ}$ 2. Huamanga: Universidad Nacional San Cristóbal de Huamanga, pp. 23-24.

2005 “Tiempos de purunrunas en la cuenca de Qaracha: violencia en la época prehispánica tardía”. En: Investigaciones en Ciencias Sociales N². Instituto de Investigación de la Facultad de Ciencias Sociales. Huamanga: Universidad Nacional San Cristóbal de Huamanga, pp. 103128.

2013 "Pukara Llaqtakuna - pueblos fortificados del periodo intermedio tardío en Ayacucho, Perú”. En: Investigación 21(1-2). Oficina General de Investigación e Innovación, Vicerrectorado Académico, Huamanga: Universidad Nacional San Cristóbal de Huamanga, pp. 317326. 
2014a "Fundación de Andamarca - Lucanas, Ayacucho. Los hermanos Mayo: mito, historia, cultura y paisaje". En: Alteritas N³, Revista de Estudios Socioculturales Andino Amazónicos. Huamanga: Universidad Nacional San Cristóbal de Huamanga, pp. 93-120.

2014b "El itinerario de colaboradores del Dr. J. C. Tello. Las cuencas del Pampas y Apurímac: Huancavelica, Ayacucho, Apurímac y Cusco”. En: Conchopata № 4. Escuela de Formación Profesional de Arqueología e Historia, Facultad de Ciencias Sociales. Huamanga: Universidad Nacional San Cristóbal de Huamanga, pp. 57-66.

2016 “Obras hidráulicas de etapa prehispánica en Huaccana, Chincheros - Apurímac”. En: Arqueología y Sociedad No 30. Museo de Arqueología y Antropología. Lima: Universidad Nacional Mayor de San Marcos, pp. 315-333. 